\author{
SANDIA REPORT \\ SAND2007-7393 \\ Unlimited Release \\ Printed Month and Year
}

\title{
Development of a Manufacturing Capability for Production of Ceramic Laser Materials
}

Terry J. Garino, James A. Voigt, Erik D. Spoerke, Diana L. Moore, Steven J. Lockwood, Pin Yang, Julie T. Gibson and Carol C. Phifer

Prepared by

Sandia National Laboratories

Albuquerque, New Mexico 87185 and Livermore, California 94550

Sandia is a multiprogram laboratory operated by Sandia Corporation, a Lockheed Martin Company, for the United States Department of Energy's

National Nuclear Security Administration under Contract DE-AC04-94AL85000.

Approved for public release; further dissemination unlimited. 
Issued by Sandia National Laboratories, operated for the United States Department of Energy by Sandia Corporation.

NOTICE: This report was prepared as an account of work sponsored by an agency of the United States Government. Neither the United States Government, nor any agency thereof, nor any of their employees, nor any of their contractors, subcontractors, or their employees, make any warranty, express or implied, or assume any legal liability or responsibility for the accuracy, completeness, or usefulness of any information, apparatus, product, or process disclosed, or represent that its use would not infringe privately owned rights. Reference herein to any specific commercial product, process, or service by trade name, trademark, manufacturer, or otherwise, does not necessarily constitute or imply its endorsement, recommendation, or favoring by the United States Government, any agency thereof, or any of their contractors or subcontractors. The views and opinions expressed herein do not necessarily state or reflect those of the United States Government, any agency thereof, or any of their contractors.

Printed in the United States of America. This report has been reproduced directly from the best available copy.

Available to DOE and DOE contractors from

U.S. Department of Energy

Office of Scientific and Technical Information

P.O. Box 62

Oak Ridge, TN 37831

Telephone: (865) 576-8401

Facsimile: $\quad$ (865) 576-5728

E-Mail: reports@adonis.osti.gov

Online ordering: http://www.osti.gov/bridge

Available to the public from

U.S. Department of Commerce

National Technical Information Service

5285 Port Royal Rd.

Springfield, VA 22161

Telephone: $\quad$ (800) 553-6847

Facsimile: (703) 605-6900

E-Mail: $\quad$ orders@ntis.fedworld.gov

Online order: $\quad$ http://www.ntis.gov/help/ordermethods.asp?loc=7-4-0\#online

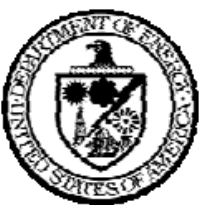


SAND2007-xxxx

Unlimited Release

Printed October 2007

\title{
Development of a Manufacturing Capability for Production of Ceramic Laser Materials
}

\author{
Terry J. Garino, James A. Voigt, Erik D. Spoerke, Diana L. Moore \\ Electronic and Nanostructured Materials Department \\ Steven J. Lockwood, Pin Yang, Julie T. Gibson \\ Ceramic and Glass Department \\ Carol C. Phifer \\ Laser Optics and Remote Sensing Department \\ Sandia National Laboratories \\ P.O. Box 5800 \\ Albuquerque, NM 87185-1411
}

\begin{abstract}
$\underline{\text { Abstract }}$
A Laboratory Directed Research and Development Program was conducted with the goal of developing a manufacturing capability for polycrystalline ceramic laser host materials. Polycrystalline transparent ceramics (e.i. Nd:YAG), fabricated by sintering of compacts of fine powder, have been recently shown to have optical properties equal to or better than traditional single crystals with advantages such as improved mechanical properties, increased range of composition and of sample size as well as lower cost. Two materials were studied in this program: Nd:YAG as a baseline material that has potential applications of interest to Sandia such as micro-lasers and graded structures, and Cr,Nd:GSGG whose radiation properties make it suitable for applications such as Direct Optical Initiation. Chemical precipitation synthesis techniques were developed for each material, based on adding metal nitrate solutions to a hydroxycarbonate precipitant solution, to produce nano-size powders with controlled and uniform stoichiometry that could be readily crystallized to the desired garnet phase. The crystalline powders were then milled ultrasonically and formed into compacts by vacuum filtration of aqueous particle suspensions that had uniform packing of the powder with minimal contamination and other defects. Sintering and uniaxial hot-pressing studies were than carried out on the powder compacts. Sintering studies on both powders showed that they commenced densification at $1200 \quad \mathrm{C}$ and could reach nominally $100 \%$ of theoretical density after sintering at or below $1500 \mathrm{C}$ for several hours. Sintering the Nd:YAG by heating directly to higher temperatures, $>1650 \mathrm{C}$, produced transparent samples that contained large pores. Sintering studies showed that pore growth mechanisms were responsible for the presence of the large pores and a multi-stage sintering approach was used to avoid large pore formation. Although samples of Cr,Nd:GSGG were sintered essentially pore-free, they remained only translucent. Transparent samples, not of laser quality, were also produced of both materials by uniaxial hot-pressing. Even though the ultimate goal of laser quality transparent ceramics was not obtained, significant progress towards developing the entire fabrication process for such materials was made and the level of understanding achieved shows what direction to follow for further improvements in optical properties.
\end{abstract}




\section{ACKNOWLEDGEMENTS}

The authors wish to express their gratitude to Gary Zender and Bonnie McKenzie (both Org. 1822) for the SEM work, to Mark Rodriguez and Ralph Tissot (both Org. 1822) for the XRD analysis, to Paul Hlava (Org. 1822) for the microprobe analysis, to Clay Newton (Org. 1825) for the uniaxial hot pressing, to Tom Hinklin (Org. 1815) and Randy Schmitt (Org. 1128) for helpful conversations, to Duane Schneider (Org. 2453) for the surface area measurements, Margaret Sanchez for optical microscopy and cold isostatic pressing and to Carter Hodges (Org. 2452) for the vacuum sintering in the Brew furnace. The authors also express their gratitude to the Sandia LDRD Program for funding this work. Sandia is a multiprogram laboratory operated by Sandia Corporation, a Lockheed Martin Company, for the United States Department of Energy under Contract DE-AC04-94AL85000. 


\section{Table of Contents}

\begin{tabular}{|l|c|}
\hline ACKNOWLEDGEMENTS & 4 \\
\hline INTRODUCTION & 7 \\
\hline EXPERIMENTAL PROCEDURE & 10 \\
\hline Powder Synthesis: Nd:YAG & 10 \\
\hline Powder Synthesis: Cr,Nd:GSGG & 12 \\
\hline Powder Processing & 13 \\
\hline Sintering and Hot Pressing & 14 \\
\hline RESULTS AND DISCUSSION & 15 \\
\hline Powder Synthesis: Nd:YAG & 15 \\
\hline Powder Synthesis: Cr,Nd:GSGG & 17 \\
\hline Nd:YAG Sintering & 20 \\
\hline Cr,Nd:GSGG Sintering & 26 \\
\hline CONCLUSIONS & 31 \\
\hline REFERENCES & 33 \\
\hline
\end{tabular}

\section{$\underline{\text { List of Figures }}$}

\begin{tabular}{|c|c|}
\hline Figure 1. The phase diagrams for the a.) $\mathrm{Y}_{2} \mathrm{O}_{3}-\mathrm{Al}_{2} \mathrm{O}_{3}$ system and the b.) $\mathrm{Gd}_{2} \mathrm{O}_{3}-\mathrm{Ga}_{2} \mathrm{O}_{3}$ & 9 \\
\hline Figure 2. Diagram of the chemical synthesis procedure used for Nd:YAG. & 11 \\
\hline Figure 3. Photograph of the experimental setup used to make the Nd:YAG powder. & 11 \\
\hline Figure 4. TGA of baseline YAG powder heated at $5^{\circ} \mathrm{C} / \mathrm{min}$ in air. & 15 \\
\hline $\begin{array}{l}\text { Figure 5. XRD pattern of baseline YAG powder after calcination at } 1000^{\circ} \mathrm{C} \text { for } 6 \mathrm{hrs} \text { showing single } \\
\text { phase garnet. }\end{array}$ & 16 \\
\hline Figure 6. SEM images of the calcined baseline YAG powder. & 16 \\
\hline Figure 7. SEM images of a compact of YAG powder made by vacuum filtration. & 16 \\
\hline Figure 8. TGA/DTA curves for GSGG precursor powders produced at different pH values. & 17 \\
\hline Figure 9. SEM images of GSGG powders produced at pH values of a.) 8.4 and b.) 7.8 . & 18 \\
\hline Figure 10. XRD patterns of calcined GSGG powders synthesized at different pH values. & 18 \\
\hline Figure 11. High-temperature XRD results on baseline GSGG precursor powder. & 19 \\
\hline Figure 12. SEM images of calcined GSGG-18 powder. & 19 \\
\hline $\begin{array}{l}\text { Figure 13. XRD patterns for baseline GGG and GSGG calcined powders showing shift in peaks due to } \\
\text { increase in lattice parameter with the presence of Sc. }\end{array}$ & 20 \\
\hline Figure 14. The densification behavior of baseline Nd;YAG and Cr.Nd:GSGG powder compacts. & 21 \\
\hline Figure 15. Photograph of YAG sample that was vacuum sintered at $1650^{\circ} \mathrm{C}$ for $5 \mathrm{hr}$. & 21 \\
\hline Figure 16. SEM images of the fracture surface of a YAG sample sintered in vacuum at $1700^{\circ} \mathrm{C}$ for $5 \mathrm{hr}$. & 22 \\
\hline Figure 17. SEM images of a YAG sample sintered at $1500^{\circ} \mathrm{C}$ for $6 \mathrm{hr}$. & 22 \\
\hline Figure 18. Pore in a sintered YAG sample showing a dihedral angle of $\sim 120^{\circ}$. & 22 \\
\hline Figure 19. YAG sample first heated to $1500^{\circ} \mathrm{C}$ for $4 \mathrm{hr}$ and then to $1800^{\circ} \mathrm{C}$ for $6 \mathrm{hr}$. & 23 \\
\hline Figure 20. YAG sample first heated to $1400^{\circ} \mathrm{C}$ for $1 \mathrm{hr}$ and then to $1500^{\circ} \mathrm{C}$ for $6 \mathrm{hr}$. & 23 \\
\hline Figure 21. XRD patterns of a stoichiometric Nd:YAG batch (\#11) that indicate $\mathrm{YAIO}_{3}$ after sintering. & 25 \\
\hline $\begin{array}{l}\text { Figure 22. SEMs of a sintered Nd:YAG powder with excess Al (batch 25) showing the presence of } \\
\text { alumina. }\end{array}$ & 25 \\
\hline Figure 23. Sintered samples of YAG-25 (5\% xs Al) to which Y was added, a.) $0.9 \% \mathrm{Y}$ and b.) $1.0 \% \mathrm{Y}$. & 25 \\
\hline Figure 24. Hot-pressed sample of YAG-25 +0.9\%Y $\left(1450^{\circ} \mathrm{C}\right.$ for $2 \mathrm{hr}$ at $\left.6 \mathrm{ksi}\right)$ & 26 \\
\hline
\end{tabular}




\begin{tabular}{|l|l|}
\hline $\begin{array}{l}\text { Figure 25. SEM image of a sintered GSGG-7 powder ( } 1450^{\circ} \mathrm{C} \text { for } 1 \mathrm{hr} \text { in vacuum) showing second } \\
\text { phase particles. }\end{array}$ & 26 \\
\hline Figure 26. SEM images of GSGG-10 sintered at $1425^{\circ} \mathrm{C}$ for $2 \mathrm{hr}(\mathrm{vac})$ then at $1575^{\circ} \mathrm{C}$ for 30 min (air). & 28 \\
\hline Figure 27. GSGG sintered at high temperature $\left(1700^{\circ} \mathrm{C}\right)$ also develops large pores. & 28 \\
\hline $\begin{array}{l}\text { Figure 28. SEM images of a hot-pressed GSGG-10 sample after air annealing for } 1 \mathrm{hr} \text { at a.) } 1250^{\circ} \mathrm{C} \text { and } \\
\text { b.) } 1350^{\circ} \mathrm{C} \text {. }\end{array}$ & 29 \\
\hline Figure 29. A hot-pressed sample of GSGG-13. & 30 \\
\hline Figure 30. XRD pattern of GSGG-15 powder calcined at $1000^{\circ} \mathrm{C}$ for 6 hrs showing single phase. & 31 \\
\hline Figure 31. XRD pattern of hot-pressed GSGG-16 showing single phase garnet. & 31 \\
\hline $\begin{array}{l}\text { Figure 32. SEM image of a polished surface of a hot-pressed (1350C for } 2 \mathrm{hr}) \mathrm{GSGG}-16 \text { sample } \\
\text { showing Sc-rich regions (dark areas). }\end{array}$ & 31 \\
\hline
\end{tabular}

\section{List of Tables}

Table 1. List of chemicals used for powder synthesis.

Table 2. The batched composition of all the $\mathrm{Cr}$,Nd:GSGG powders synthesized.

Table 3. Sintered densities of YAG-26 samples.

Table 4. Summary of sintering results on various Cr.Nd:GSGG samples.

Table 5. Summary of microprobe results on $\mathrm{Cr}, \mathrm{Nd}$ :GSGG samples. 


\section{Introduction}

Optical engineering technology, such as direct optical initiation (DOI), is a key to future advanced firing/detonation systems. A critical component of the DOI firing set architecture is a solid-state laser that relies on a unique, radiation hard Nd-doped gadolinium scandium gallium garnet (Nd:GSGG) single crystal material. Presently, a sole-source supplier using an expensive, inherently problematic and unreliable Czochralski method grows the GSGG single crystals on an as-needed basis. Fabrication of single crystals of GSGG from the high-temperature melt involves numerous processing problems such as volatilization of gallium, inclusions of iridium particles from the crucible, a tendency toward spiral growth, crystal defects such as dislocations, poor control of the dopant levels, nonuniform distribution of dopants, boule cracking during cool-down, and so forth. ${ }^{1}$ The ability to replace the GSGG single crystal with a transparent ceramic counterpart will not only eliminate these problems, it would provide many other cutting edge opportunities. In addition, the preparation of larger samples would be possible and the production of transparent GSGG in ceramic form would potentially be less costly since it is a lower temperature, shorter time process that would generate less rejected material. The primary goal of this work was to develop an in-house production capability to prepare Nd:GSGG in transparent ceramic form. Although to date no transparent, laser-quality ceramic GSGG has been reported, the Japanese company Konoshima has commercialized laser-quality ceramic Nd-doped yttrium aluminum garnet (Nd-YAG), a non radiation-hard laser host material, with optical, mechanical and thermal properties equal to or better than single crystals. ${ }^{2}$ This material, produced in collaboration with Baikowski, is produced by sintering fine YAG powder. Because of the more extensive information available concerning transparent ceramic YAG and because Sandia has potential applications for this material in the area of micro-optics, for example, this project started with work on YAG in the first FY and then, in years two and three, focused on GSGG by building on the knowledge base developed from the work on YAG. Therefore, a brief review of the literature on both of these materials is given below.

Because of the scattering of light, most polycrystalline ceramic materials are opaque. Ceramics are made starting with powder compacts that have a high degree of porosity $(\sim 50 \%)$ that must be removed during the high temperature sintering process. Typically, it is the residual pores that may be either trapped inside grains or at grain boundaries that are the primary source of light scattering. In fact, to achieve scattering low enough for laser host applications the residual porosity must be in the 1 part per million range ${ }^{3}$, as compared to the 1 to $5 \%$ porosity that normally remains after sintering technical ceramics. The difficulty in achieving this extremely low level of residual porosity has been the main challenge to producing laserquality transparent ceramics. Typically, sintering must be performed under vacuum, at least to the point where closed pores ( $\sim 92 \%$ relative density), to avoid trapping gas in the pores since the trapped gas will compress as the pores shrink and exert a stress that stops further sintering. Other sources of light scattering in ceramics include second phase particles, birefringence and grain boundaries.

Yttrium aluminum garnet, $\mathrm{Y}_{3} \mathrm{Al}_{5} \mathrm{O}_{12}$, doped with various rare earth elements such as $\mathrm{Nd}$, has been used in single crystal form as a laser host for many years. In fact, Nd:YAG is the dominant laser host material in industrial applications due to its superior properties. ${ }^{3}$ However, the growth of large Nd:YAG crystals can take 40 days and because of defects, typically less than $25 \%$ of the grown crystal is usable. Also, the limited solubility of $\mathrm{Nd}(1 \%)$ in single crystals limits the absorption of the excitation light, limiting the efficiency. For these reasons, work began on fabricating ceramic Nd:YAG for laser applications in the mid-1990s. ${ }^{4-6}$ The $\mathrm{Al}_{2} \mathrm{O}_{3}-\mathrm{Y}_{2} \mathrm{O}_{3}$ phase diagram, showing the YAG compound, is shown in Figure 1a (note that other phase diagrams show the $1: 1$ phase as stable to room temperature). ${ }^{7}$ As the diagram shows, 
YAG is a line compound meaning that no excess alumina or yttria is soluble in YAG. Therefore any deviation from the exact desired stoichiometry will result in the presence of a second phase which, as mentioned above, will result in unacceptable light scattering. YAG has a cubic crystal structure with a lattice parameter of $12.0089 \AA$ and a theoretical density of $4.554 \mathrm{~g} / \mathrm{cm}^{3}$. When doped with 1.1 at $\% \mathrm{Nd}$, which sits on the Y sites in the lattice, the lattice parameter increases to $12.0115 \AA$ and the density to $4.565 \mathrm{~g} / \mathrm{cm}^{3}$.

Ikesue et al. ${ }^{4-6}$ were the first to report laser quality sintered Nd:YAG ceramics, using a mixed oxide approach. They mixed high-purity, sub-micrometer powders of the oxides with tetraethyl orthosilicate as a source of silica which served as a sintering aid. The mixture was ball-milled using high-purity alumina media in ethanol for $12 \mathrm{hr}$. This step undoubtedly introduced some additional alumina from the media which needed to be compensated for by adding enough excess yttria. The mixture was then spray dried, cold isostatically pressed and vacuum sintered between $1750^{\circ}$ and $1800^{\circ} \mathrm{C}$ for $20 \mathrm{hr}$. This process resulted in laser-quality material with $\sim 50 \mathrm{~m}$ grain size. More recently, researchers at Konoshima (Konoshima Kagaku Kogyo, Osaka, Japan) and elsewhere have used coprecipitation to synthesize powders that were then processed to transparent YAG ceramics. In coprecipitation, a solution containing dissolved salts of the metals $\mathrm{Al}, \mathrm{Y}$ and $\mathrm{Nd}$ is mixed with a precipitant solution that causes the metals to precipitate out as a fine precursor powder in which the metals are mixed on the atomic scale. The precursor must be filtered, dried and then calcined at $900^{\circ}$ to $1200^{\circ} \mathrm{C}$ to form the desired cubic crystalline phase. Lu et al. ${ }^{8,9}$ ] first reported the fabrication of transparent $\mathrm{Nd}$ :YAG from coprecipitated powders made by the urea method, but still used $\mathrm{SiO}_{2}$ as a sintering aid. Since then, reseachers at Konoshima ${ }^{10,11}$ and Li et al. ${ }^{12,13}$ have used ammonium hydrogen carbonate as the precipitant and have succeeded in producing transparent YAG without sintering aid additives (at least in the work of Li et al.).

Gadolinium gallium garnet (GGG), $\mathrm{Gd}_{3} \mathrm{Ga}_{5} \mathrm{O}_{12}$, has the same cubic crystal structure as YAG, with the yttrium replaced by gadolinium and the aluminum by gallium. The phase diagram of the gadolinium oxide-gallium oxide system, shown in Figure 1b, indicates a congruent melting temperature of $\sim 1740^{\circ} \mathrm{C}$ and a small degree of solubility of excess $\mathrm{Gd}_{2} \mathrm{O}_{3}$ in GGG. ${ }^{14}$ As with YAG, the GGG laser host material must be doped with neodymium, typically $1.67 \%$ for single crystals (the polycrystalline concentration may be significantly different). Co-doping GGG with chromium (1.25 to 2.5\%) improves the lasing performance. ${ }^{15}$ The $\mathrm{Cr}^{3+}$ ions absorb photons over a wider spectral range, and then they transfer this energy non-radiatively to the $\mathrm{Nd}^{3+}$ ions. However, the addition of chromium to GGG causes defects in the crystals that lead to a deterioration in the optical quality. These defects do not occur when $40 \%$ of the gallium is replaced by scandium, yielding $\mathrm{GSGG}, \mathrm{Gd}_{3} \mathrm{Sc}_{2} \mathrm{Ga}_{3} \mathrm{O}_{12}$, due to the lattice parameter increase provided by the scandium addition. (12.583 $\AA$ compared to $12.376 \AA$ ). How the addition of scandium oxide affects the phase relations is not known as a ternary diagram has not been published. GSGG doped with $\mathrm{Cr}^{3+}$ and $\mathrm{Nd}^{3+}$ is a laser host material that is two to four times more efficient than $\mathrm{Nd}: \mathrm{YAG}^{16,17}$ and, more importantly, it shows increased laser output immediately after exposure to radiation ${ }^{18}$, as opposed to $\mathrm{Nd}$ :YAG which darkens ${ }^{19}$.

In recent years, there have been several studies on the production of ceramic GGG. In one of the earliest studies, Hellstrom et al. ${ }^{20}$ prepared ceramic GGG by solid state reaction of the oxides. More recently, coprecipitation has been used with either ammonium hydroxide ${ }^{21-22}$ or ammonium hydrogen carbonate ${ }^{23}$ as the precipitant. None of these studies reported the production of transparent ceramic GGG. To the authors' knowledge, there have not been any reports of work on ceramic GSGG. 
The goal of this LDRD program was to develop an in-house manufacturing capability for laser-quality ceramic Nd:YAG and Cr,Nd:GSGG. Our strategy was to first focus on Nd:YAG because there was more available literature on this material and because it is less complex than the Cr,Nd:GSGG (three metals instead of five). During the first year of the program, a baseline synthesis route to produce high-purity, nano-size precursor powders was developed for $\mathrm{Nd}, \mathrm{YAG}$, building on the previous studies mentioned above. The calcining, processing and sintering of this material were studied into year two, when work began on Cr,Nd:GSGG synthesis. In the final year, the baseline Cr,Nd:GSGG synthesis was established and the calcining, processing and sintering of this material was studied, building on what we learned from the processing of the Nd:YAG.

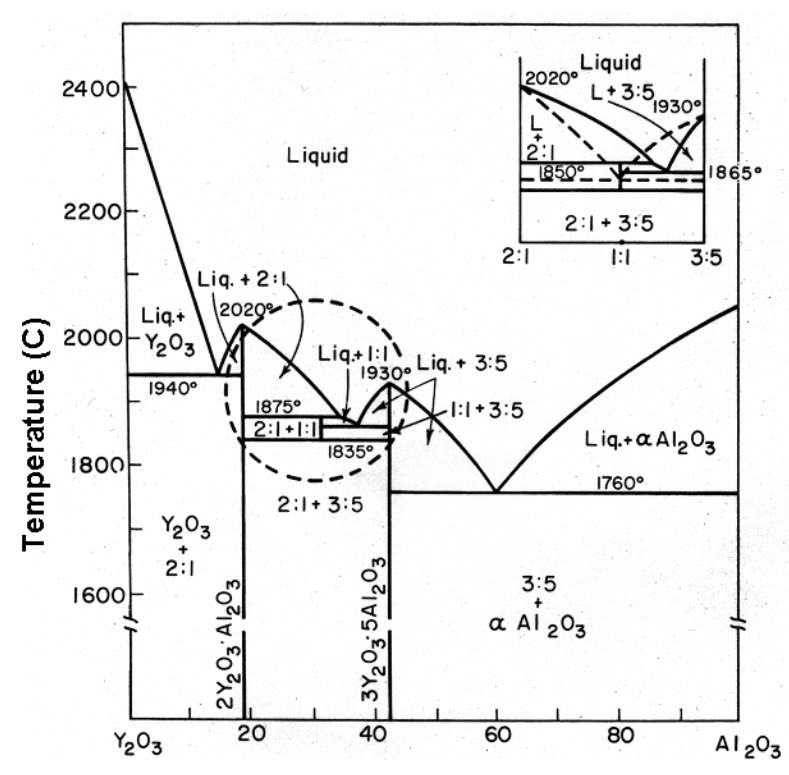

a.

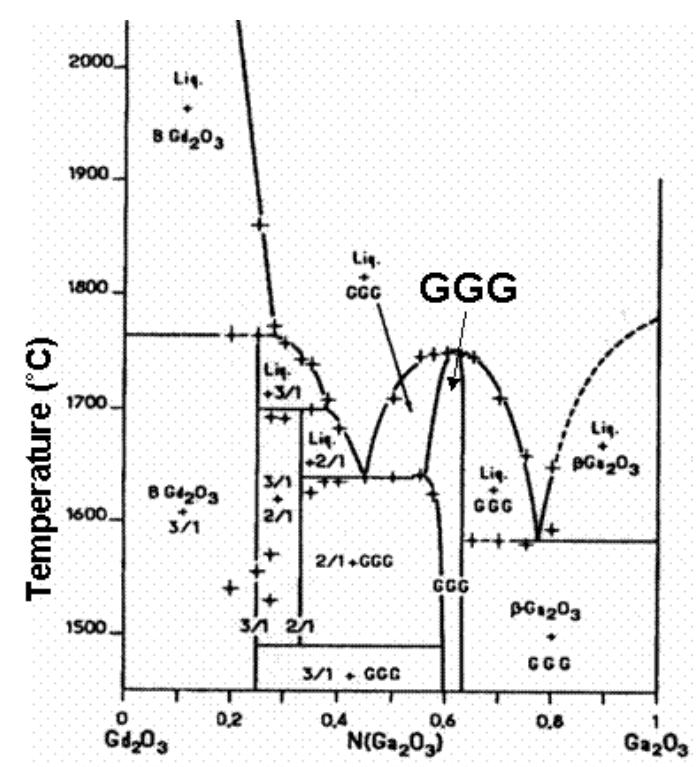

b.

Figure 1. The phase diagrams for the a.) $\mathrm{Y}_{2} \mathrm{O}_{3}-\mathrm{Al}_{2} \mathrm{O}_{3}$ system and the b.) $\mathrm{Gd}_{2} \mathrm{O}_{3}-\mathrm{Ga}_{2} \mathrm{O}_{3}$ system. 


\section{Experimental Procedure}

\section{Powder Synthesis: Nd:YAG}

Based on the literature review ${ }^{10-12}$ and our own experience in developing solution routes to ceramic powders, the hydroxycarbonate and oxalate precipitation routes were chosen for initial investigation for the chemical precipitation of $\mathrm{Nd}$ :YAG. Initial results at the small batch-scale showed that the hydroxycarbonate route produced finer, more sinterable powders. Since there were no obvious advantages with regard to filterability for the oxalate-based system, as is often seen, the hydroxycarbonate route was chosen for further development.

A baseline solution synthesis process flow chart and a picture of the experimental setup used are shown in Figs. 2 and 3, respectively. The reverse strike method was used in which the metal salt solution is added over several minutes to the precipitant solution. Ammonium carbonate was chosen as the precipitant instead of ammonium hydrogen carbonate because a higher purity source was found for it. Nitrates were used as the metal salts, since the nitrate anion is typically easier to completely remove than the chloride anion since the nitrates decompose thermally. The sources of the metals were purchased as either a high purity nitrate ( $\mathrm{Al})$ or oxide $(\mathrm{Y}, \mathrm{Nd})$, for those not available as high purity nitrates (see Table 1). The aluminum nitrate solution was made by simply dissolving the desired amount of $\mathrm{Al}\left(\mathrm{NO}_{3}\right)\left(\mathrm{x} \mathrm{H}_{2} \mathrm{O}\right)$ salt in water in a beaker with slight heating on a hotplate and then, upon cooling, volumetrically diluting the solution to the desired concentration with water. To produce the yttrium nitrate solution, the $\mathrm{Y}_{2} \mathrm{O}_{3}$ oxide powder was mixed with water and heated to boiling in a covered beaker with agitation (stir bar). The desired amount of concentrated nitric acid was cautiously and slowly added drop wise to the boiling slurry while stirring, taking care not to lose the boil (sputtering and splattering occurs with the addition of the acid). The beaker remained covered with a watch glass between additions to help maintain temperature. Upon complete dissolution of the powders, the solution was allowed to cool and quantitatively transferred to a volumetric flask. A similar procedure was used for the $\mathrm{Nd}$, which was slightly easier to dissolve. Metal nitrate stock solutions were then mixed together in the desired ratio. The metal stoichiometry of this solution was that of the final complex oxide to be prepared, and was $\mathrm{Y}_{2.967} \mathrm{Nd}_{0.033} \mathrm{Al}_{5} \mathrm{O}_{12}$, except for several batches that were made with excess $\mathrm{Al}$ (see below).

The metal salts solution was filtered through a $0.2 \mathrm{~m}$ filter and was pumped using a peristaltic pump into a precipitation reaction vessel containing a similarly filtered ammonium carbonate precipitant solution. The metal salts solution was injected into the head of a high-speed shear mixer (IKA Ultra-Turrax T50, Janke and Kunkel, Staufen, Germany with S50-G45FF tool) to insure immediate and vigorous contact with the precipitant. Initial experiments investigated parameters that included the carbonate to metal ratio, final $\mathrm{pH}$, precipitate aging, and precipitate washing. The results of these studies established a baseline of experimental parameters that reproducibly prepared phase pure Nd-doped YAG powders. Baseline parameters included a metals concentration of $0.5 \mathrm{M}$ and an ammonium carbonate concentration of $0.8 \mathrm{M}$, for a carbonate to metals ratio of 1.8. For a standard batch that resulted in $50 \mathrm{~g}$ of oxide powder, $1.4 \mathrm{~L}$ of metal solution was added at $50 \mathrm{ml} / \mathrm{min}$ (for $\sim 30 \mathrm{~min}$ ) to $1.5 \mathrm{~L}$ of the ammonium carbonate precipitant solution. The $\mathrm{pH}$ of the reaction was monitored using a $\mathrm{pH}$ meter in the precipitant solution. The initial $\mathrm{pH}$ was $\sim 9.0$ and decreased to 6.2-6.5 once all the metals solution had been 
added. At this point, ammonium hydroxide $(25 \%, 50$ to $100 \mathrm{~g})$ was added to increase the $\mathrm{pH}$ back to $\sim 9.0$. The mixture was then aged for $\sim 21 \mathrm{hr}$ while moderately stirring with a paddle $(\sim 90$ RPM), at which point its $\mathrm{pH}$ had risen slightly to $\sim 9.2$.

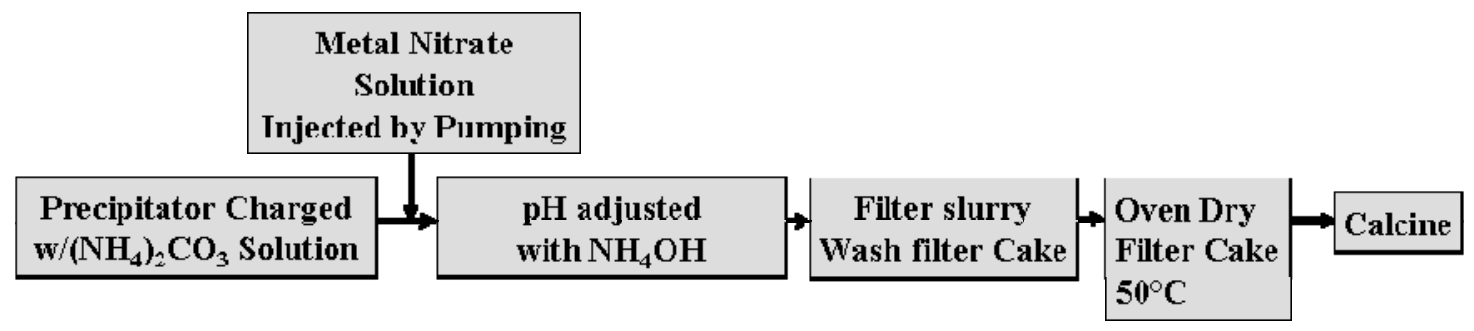

Figure 2. Diagram of the chemical synthesis procedure used for Nd:YAG.

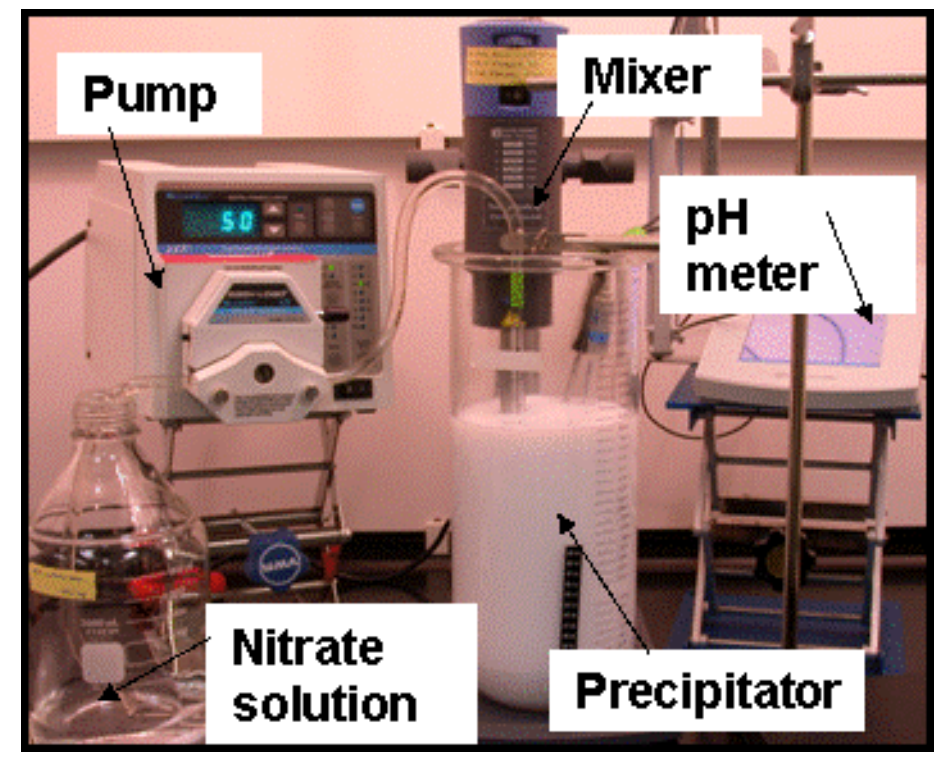

Figure 3. Photograph of the experimental setup used to make the Nd:YAG powder.

The precipitated precursor powders were collected by vacuum filtration after the aging. The precursor powders were washed with water, ethanol and then acetone, without reslurrying between washes. The filter cake was then left under vacuum overnight. After drying at $50^{\circ} \mathrm{C}$ for $2 \mathrm{hr}$, the powder was coarsely ground with a mortar and pestle before calcining between $900^{\circ}$ and $1150^{\circ} \mathrm{C}$ in air to decompose the precursor and to crystallize the garnet phase. The precursor powders were characterized using scanning electron microscopy (SEM) and simultaneous thermal gravimetric and differential thermal analyses (STA 409 PC, Netzsch, Selb, Germany). The calcined powders were analyzed using BET surface area measurement, x-ray diffraction (XRD) and SEM. A total of 26 batches of YAG powder were made although only 8 of them were $50 \mathrm{~g}$ in size made using the baseline process (batches $8,11-15$, and 24-26). Of these, all were batched stoichiometrically except for batches 24 and 25 that had 5\% excess Al and batch 26 that had $4.75 \%$ excess alumina. The reasons for these composition changes will be discussed below. 
Table 1. List of chemicals used for powder synthesis.

\begin{tabular}{|l|l|c|}
\hline \multicolumn{1}{|c|}{ Chemical } & \multicolumn{1}{c|}{ Source } & Purity \\
\hline Aluminum Nitrate, Puratronic & Alfa Aesar, Ward Hill MA & 99.999 \\
\hline Ammonium Carbonate, Puratronic & Alfa Aesar, Ward Hill MA & 99.999 \\
\hline Ammonium Hydroxide & Alfa Aesar, Ward Hill MA & 99.99 \\
\hline Ammonium Sulfate, Puratronic & Alfa Aesar, Ward Hill MA & 99.999 \\
\hline Chromium (III) Nitrate, Puratronic & Alfa Aesar, Ward Hill MA & 99.999 \\
\hline Gallium Oxide, Puratronic & Alfa Aesar, Ward Hill MA & 99.999 \\
\hline Gadolinium Oxide, REacton & Alfa Aesar, Ward Hill MA & 99.999 \\
\hline Neodymium Oxide & Acros, Geel, Belgium & 99.999 \\
\hline Nitric Acid & Alfa Aesar, Ward Hill MA & 99.999 \\
\hline Scandium Oxide, Reacton & Alfa Aesar, Ward Hill MA & 99.99 \\
\hline Scandium Oxide & Stanford Materials, Aliso Vieja, CA & 99.9995 \\
\hline Yttrium Oxide, REacton & Alfa Aesar, Ward Hill MA & 99.999 \\
\hline
\end{tabular}

\section{Powder Synthesis: Cr,Nd:GSGG}

The Cr,Nd:GSGG powder synthesis technique was similar to that used for the Nd:YAG powder and to literature reports ${ }^{23}$ in that it involved adding a solution of metal nitrates to an ammonium carbonate precipitant solution. High purity metals nitrates were either used directly when available (Cr) or were synthesized from the metal oxides ( $\mathrm{Gd}, \mathrm{Ga}, \mathrm{Sc}$, and $\mathrm{Nd}$ ). See Table 1 for more information. The chromium (III) nitrate was dissolved in water while the Nd solution was prepared as described above for the Nd:YAG. The procedure used for the Gd was similar to that used for the $\mathrm{Y}$ described above. In this case, if the dissolution was slightly incomplete (some turbidity) the solution was filtered and gravimetrically assayed. The Ga and Sc oxides were more difficult to dissolve, so a similar reflux process was used for both. The oxide powder/water/nitric acid slurries were reacted in a three neck round bottom flask equipped with a condenser. The acid to metal ratio was 3.3:1 with the Sc or Ga concentration during dissolution ranging from $\sim 0.6$ to $\sim 1.6 \mathrm{M}$. The mixture was heated to boiling and refluxed for several hours. Since complete dissolution was not achieved with either powder, the turbid solutions were filtered (0.2 $\mathrm{m}$ filter) and gravimetric assays performed.

The target composition for the $\mathrm{Cr}$,Nd:GSGG powder was $\mathrm{Gd}_{2.950} \mathrm{Nd}_{0.050} \mathrm{Sc}_{1.975} \mathrm{Cr}_{0.025} \mathrm{Ga}_{3} \mathrm{O}_{12}$. The baseline process that yielded $\sim 10 \mathrm{~g}$ of oxide powder will be described here. Results of variations to this baseline are discussed below. The metal nitrate solutions were mixed together in the desired ratios to give a total metals concentration of $\sim 0.25 \mathrm{M}$. The precipitant solution $(800 \mathrm{ml})$ contained $1.6 \mathrm{M}\left(\mathrm{NH}_{4}\right)_{2} \mathrm{CO}_{3}$ that was adjusted in $\mathrm{pH}$ from $\sim 8.8$ to $\sim 7.6$ by adding concentrated nitric acid dropwise. This lowered the concentration to $\sim 1.45 \mathrm{M}$. The metal nitrate solution $(\sim 330 \mathrm{ml})$ was added at $\sim 6 \mathrm{ml} / \mathrm{min}$ to the stirred precipitant solution at room temperature and the final carbonate to metal ratio was 10:1. The $\mathrm{pH}$ of the reaction was monitored using a $\mathrm{pH}$ meter and was adjusted with concentrated nitric acid from 6.8-7.0, after the last of the metal nitrate solution was added ( $\sim 50 \mathrm{~min})$, to 6.5 . The slurry was then aged for $\sim 2 \mathrm{hr}$ while keeping the $\mathrm{pH}$ constant at 6.5 by adding more concentrated nitric acid. 
After the aging, the powder was collected by vacuum filtration using a medium frit filter. The filter cake was washed with degassed and purged deionized water and then with ethanol before drying at $\sim 62^{\circ} \mathrm{C}$. The dried cake was then broken up with a mortar and pestle prior to calcination at $900^{\circ}$ to $1000^{\circ} \mathrm{C}$. The precursor powders were characterized using scanning electron microscopy (SEM) and simultaneous thermal gravimetric and differential thermal analyses (STA 409 PC, Netzsch, Selb, Germany). The calcined powders were analyzed using BET surface area measurement, $x$-ray diffraction (XRD) and SEM.

The baseline process was initially developed on Nd:GGG without Sc and Cr. Once these were incorporated, a total of 22 batches were synthesized, not all of which were the standard $10 \mathrm{~g}$. One larger batch (26g, batch \#9) was attempted by essentially scaling up the baseline synthesis using larger volumes. However, after calcination this powder was not single phase and was found to have a much larger $(\sim 1 \mathrm{~m})$ particle size after ultrasonic milling, and was therefore not used. Batches 1 to 12 were synthesized by Org. 1816 with four being $9 \mathrm{~g}$ batches and the other batches had smaller size (except \#9). All subsequent batches, all 10 g, were synthesized by Org. 2454. Several changes in the composition were made in response to results on the stoichiometry of previous batches which will be discussed below. The target composition of all the batches is given in Table 2.

Table 2. The batched composition of all the Cr,Nd:GSGG powders synthesized.

\begin{tabular}{|l|l|l|}
\hline $\begin{array}{l}\text { Cr,Nd:GSGG } \\
\text { batch \# }\end{array}$ & \multicolumn{1}{|c|}{ Batched Composition } & \multicolumn{1}{c|}{ Note } \\
\hline 1 to 9 & $\mathrm{Gd}_{2.95} \mathrm{Nd}_{0.050} \mathrm{Sc}_{1.975} \mathrm{Cr}_{0.025} \mathrm{Ga}_{3} \mathrm{O}_{12}$ & initial target composition \\
\hline 10 to 12 & $\mathrm{Gd}_{2.891} \mathrm{Nd}_{0.050} \mathrm{Sc}_{1.975} \mathrm{Cr}_{0.025} \mathrm{Ga}_{3} \mathrm{O}_{12}$ & $2 \%$ deficient Gd \\
\hline 13 & $\mathrm{Gd}_{2.796} \mathrm{Nd}_{0.050} \mathrm{Sc}_{2.37} \mathrm{Ga}_{3} \mathrm{O}_{12}$ & $\begin{array}{l}5.2 \% \text { deficient in } \mathrm{Gd}, \text { no } \mathrm{Cr}, 20 \% \\
\text { excess Sc }\end{array}$ \\
\hline 14 to 21 & $\mathrm{Gd}_{2.796} \mathrm{Nd}_{0.050} \mathrm{Sc}_{2.345} \mathrm{Cr}_{0.025} \mathrm{Ga}_{3} \mathrm{O}_{12}$ & $\begin{array}{l}5.2 \% \text { deficient in } \mathrm{Gd}, 18.7 \% \\
\text { excess Sc }\end{array}$ \\
\hline 22 & $\mathrm{Gd}_{2.796} \mathrm{Nd}_{0.050} \mathrm{Sc}_{2.146} \mathrm{Cr}_{0.025} \mathrm{Ga}_{3} \mathrm{O}_{12}$ & $\begin{array}{l}5.2 \% \text { deficient in } \mathrm{Gd}, 8.6 \% \\
\text { excess Sc }\end{array}$ \\
\hline
\end{tabular}

\section{Powder Processing}

Milling of YAG powders was initially attempted using either spex milling (YSZ jar and ball), ball milling (with either alumina of high-purity YSZ media) or attritor milling (YSZ media). Due to contamination from the media and also sample size concerns in the case of the spex mill, these processes were abandoned in favor of ultrasonication using a Misonix Sonicator 3000 (Misonix Inc., Farmingdale, NY). Sonication was also used for the GSGG powders. A sapphiretipped ultrasonic horn ( 0.5 inch diameter) was used to disperse the calcined powder in water. The use of the sapphire tip prevented the normal titanium contamination resulting from tip erosion. Clear plastic tape was used to cover the horn, except for the sapphire tip, to prevent contact of the slurry with the metal horn to further limit any contamination. For the YAG powders, a polyelectrolyte dispersant (ammonium salt of poly(acrylic) acid, Darvan 821, R.T. Vanderbilt Co., Norwalk, CT) was added at $\sim 5$ wt $\%$ concentration prior to sonication. For the 
GSGG powder, this dispersant was found to leach the $\mathrm{Cr}$ from the powder and so sorbitol, a polysaccharide, was used instead at a similar concentration. A typical procedure used for sonic milling was to mix $\sim 10 \mathrm{~g}$ of powder with $30 \mathrm{ml}$ of deionized water and $0.5 \mathrm{ml}$ of the dispersant in a centrifuge tube or small glass bottle and then sonicate at power settings of 7, 8, 9 and 10 for two 1 min periods each. During sonication the mixture was stirred with a magnetic stirrer and the sonicator was pulsed, typically on for $10 \mathrm{sec}$ and then off for $5 \mathrm{sec}$. Particle size measurements were performed on the powders in dilute aqueous suspension after sonication (CAPA 700, Horiba, Kyoto, Japan). In some cases, gravitational settling or slow centrifugation were used to remove larger $(>1 \mathrm{~m})$ particles from the slurries.

The dispersed powders were formed directly into compacts by vacuum filtration since this type of process produces a much more uniform microstructure than is typically achieved by pressing a

dry powder. ${ }^{24-27}$ The slurries were vacuum cast to form compacts using $0.2 \mathrm{~m}$ filters (Nyaflo nylon membrane filters, Pall Corp., East Hills, NY) over the glass frit or metal mesh in the filtration funnels, which were either 0.62 or 1.38 inches in diameter. House vacuum was used and the inner surfaces of the funnels near where the compact formed were coated with a lubricant (Pam cooking spray; applied with a tissue) to prevent the compacts from sticking to the glass funnel walls and cracking during drying. Once the filtration was complete, the compacts were air-dried. During the drying, the compacts would pull away from the funnel walls due to drying shrinkage. The compacts were removed from the funnels to complete drying. Once dry, the compacts were cold isostatically pressed at $30 \mathrm{ksi}$.

\section{Sintering and Hot Pressing}

The compacts were then heated in air at $2^{\circ} \mathrm{C} / \mathrm{min}$ from $250^{\circ} \mathrm{C}$ to $600^{\circ} \mathrm{C}$ to pyrolize the dispersant. The shrinkage behavior during sintering of the parts of some compacts was measured using optical dilatometry during heating at $10^{\circ} \mathrm{C} / \mathrm{min}$ to $1450^{\circ} \mathrm{C}$. Several different furnaces were used to sinter samples including: 1.) a high-temperature, high-vacuum furnace (Model 414-20, Richard D. Brew and Company, Inc.), 2.) a small (0.5 inch ID) Pt-would tube furnace (Dupont TGA furnace) capable of $1500^{\circ} \mathrm{C}$ with rough vacuum ( 200 millitorr), 3.) a box furnace (Lindberg, Watertown, WI) capable of $1700^{\circ} \mathrm{C}$ in air and 4.) a large tube furnace (2 inch ID, CTF 18 , Carbolite, Hope Valley, England) capable of $1450^{\circ} \mathrm{C}$ in vacuum (because of alumina tube collapse at higher temperatures) and $1800^{\circ} \mathrm{C}$ in air. Furnace \#1, the ideal furnace for sintering since it had high vacuum capability to high temperature, was damaged and not available for use during nearly all of the final year of the project. Samples were placed on either clean $99 \%$ alumina crucibles or Pt foil for sintering at $<1550^{\circ} \mathrm{C}$ and were surrounded by coarse powder of the same composition for higher temperature sintering. Samples were typically heated under vacuum for either the entire run (furnace \#1) or for an initial schedule that resulted in only closed porosity (furnaces \#2 and \#4) before heating in air to higher temperatures.

Some samples were uniaxially hot-pressed (Centorr, Nashua, NH) using graphite dies either 0.5 or 1 inch in diameter. The pressing was performed under a vacuum of $\sim 20$ millitorr. The applied pressure was $6 \mathrm{ksi}$. The heating rate was $10^{\circ} \mathrm{C} / \mathrm{min}$ and the soak temperature was typically $1450^{\circ} \mathrm{C}$ for YAG and $1350^{\circ} \mathrm{C}$ for GSGG. Disks of either Pt or Mo were placed between the sample and disks of Grafoil (0.05" thick, UCAR Carbon Co., Wilmington, DE) that contacted the plungers to prevent direct contact between the samples and graphite. For YAG 
either Pt or Mo could be used. For GSGG, Pt seemed to lead to cracking of the sample when the temperature was above $1250^{\circ} \mathrm{C}$ so the Mo was used in these cases and did not lead to cracking. After hot-pressing, samples, especially those of GSGG were somewhat dark due to slight reduction or carbon contamination and so were annealed in air at $\sim 1100^{\circ} \mathrm{C}$.

Sintered and hot-pressed samples were characterized using XRD and SEM. The density of samples was determined using the Archimedes method to an accuracy of $\sim 0.005 \mathrm{~g} / \mathrm{cm}^{3}$. Energy Dispersive X-Ray Spectroscopy (EDS) and Electron Microprobe were performed on sintered samples and hot-pressed samples. The uv-vis transmission spectra of some Cr,Nd:NGSGG samples were obtained using a spectrophotometer.

\section{Results and Discussion}

\section{Powder Synthesis: Nd:YAG}

The baseline Nd:YAG synthesis procedure produced a precursor hydroxycarbonate powder that lost $\sim 40 \%$ mass after drying (see Figure 4), most of which occurred below $300^{\circ} \mathrm{C}$. After calcination at $1000^{\circ} \mathrm{C}$ for $6 \mathrm{hrs}$, the powder crystallized to the garnet structure and was phase pure by powder XRD (see Figure 5). The BET surface area of the powder was $\sim 31 \mathrm{~m}^{2} / \mathrm{g}$, which corresponds to an equivalent spherical diameter of $110 \mathrm{~nm}$. This was consistent with the SEM images (see Figure 6) that showed the powder to consist of somewhat irregularly-shaped ultimate particles $\sim 100 \mathrm{~nm}$ in size that formed larger aggregates. These aggregates were broken apart by the ultrasonic milling to give typical average measured particle size in suspension of $0.4 \mathrm{~m}$. Compacts of the calcined, ultrasonically milled $\mathrm{Nd}$ :YAG powder made by vacuum filtration were uniform and free of large pores or other defects, as shown in Figure 7. After cold isostatic pressing, the compacts had a relative green density of $\sim 42 \%$, a fairly low value due to the fact that each particle was an aggregate of smaller particles.

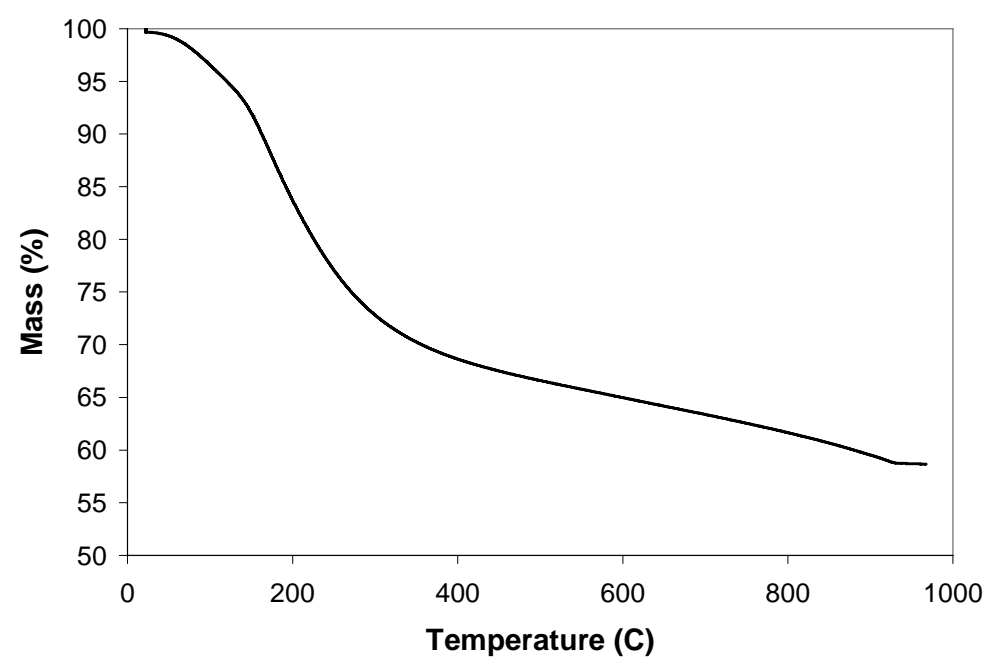

Figure 4. TGA of baseline YAG powder heated at $5 \mathrm{C} / \mathrm{min}$ in air. 


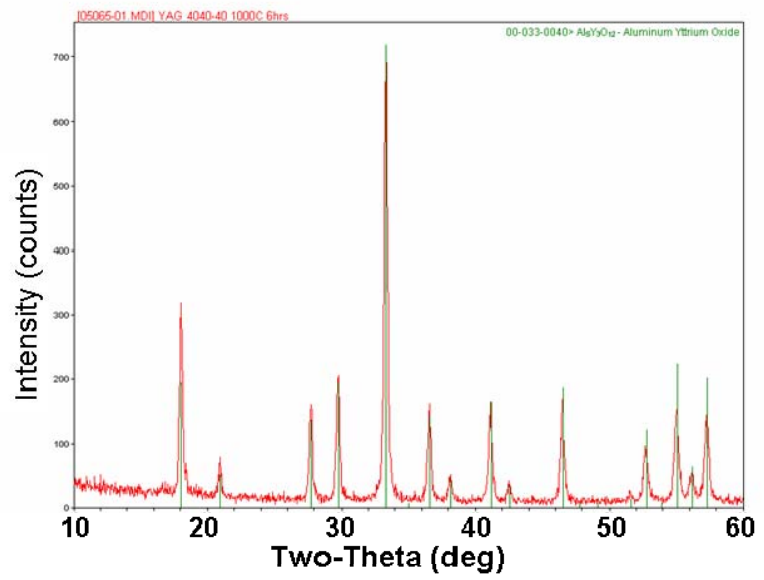

Figure 5. XRD pattern of baseline YAG powder after calcination at $1000 \mathrm{C}$ for $6 \mathrm{hrs}$ showing single phase garnet.
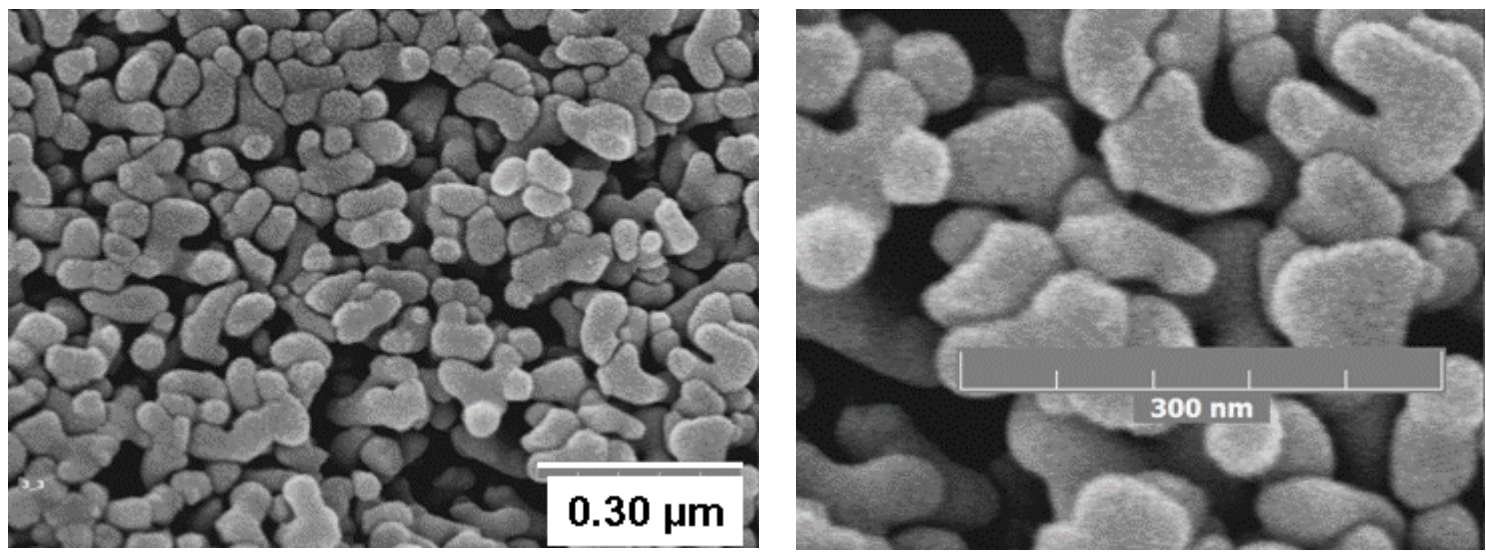

Figure 6. SEM images of the calcined baseline YAG powder.
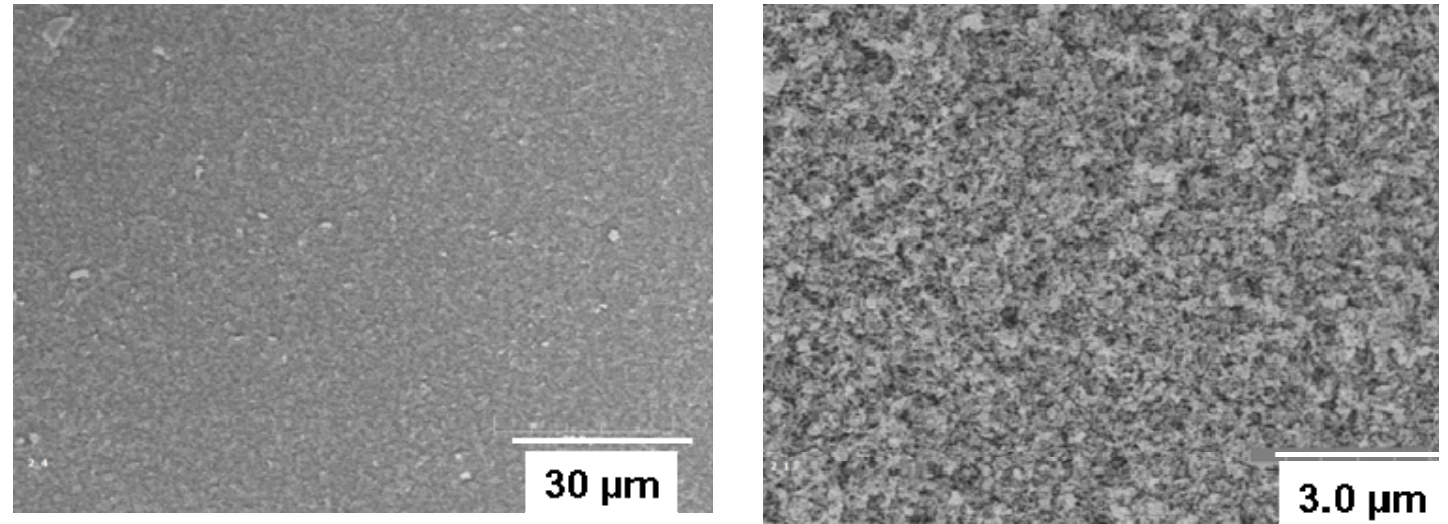

Figure 7. SEM images of a compact of YAG powder made by vacuum filtration. 
In addition to the Nd:YAG baseline synthesis conditions, a number of batches with modified synthesis conditions were produced. The results of these batches are mentioned for completeness even though they did not yield single phase YAG powder after calcination. In an early variation, the $\mathrm{pH}$ of the reaction was held constant at 9.0 during the precipitation reaction. This was accomplished by using a $\mathrm{pH}$ controller during the pumping of the metals solution such that when the $\mathrm{pH}$ fell below its desired set point, base was added. After calcination, the samples in which $\mathrm{pH}$ was controlled throughout the precipitation process were seen to contain large amounts of $\mathrm{Y}_{2} \mathrm{O}_{3}$ and $\mathrm{Al}_{2} \mathrm{Y}_{4} \mathrm{O}_{9}$, along with the garnet phase. In another series of batches, a variety of parameters were modified. The ammonium carbonate concentration was increased to 1.6 $\mathrm{M}$ and the precipitant to metals ratio was 5.4. Stirring was used instead of shear mixing and the metal solution was added ten times slower $(5 \mathrm{ml} / \mathrm{min})$. The target $\mathrm{pH}$ was lowered from 9 to 8 and the washing procedure was modified. In one batch, alum $\left.\left(\mathrm{KAl}\left(\mathrm{SO}_{4}\right)_{2} \quad 12 \mathrm{H}_{2} \mathrm{O}\right)\right)$ was used as the aluminum source. After calcination, all of these modified batches were not single phase, although in some cases, a single phase was achieved after heating to higher temperatures, $\left(\sim 1500^{\circ} \mathrm{C}\right)$.

\section{Powder Synthesis: Cr,Nd:GSGG}

The importance of the $\mathrm{pH}$ during the Cr:Nd:GSGG synthesis procedure is shown in Figure 8-10. Although the precursor powders produced at the $2 \mathrm{pH}$ 's had only slightly different thermal behavior during heating (Figure 8), their morphologies were quite different after calcination at $900^{\circ} \mathrm{C}$ for $5 \mathrm{hr}$ (Figure 9), with the lower $\mathrm{pH}$ producing much finer and more uniform powder. Both powders lost mass rapidly between $\sim 100^{\circ}$ and $\sim 200^{\circ} \mathrm{C}$, accompanied by an endothermic reaction. The final mass loss was $\sim 37 \%$ for the $\mathrm{pH} 7.8$ powder, a few percent less than for the other powder. When the $\mathrm{pH}$ was 8.4 , the powder after calcination was multi-phase whereas single phase powder was produced after calcination at $1000^{\circ} \mathrm{C}$ for $10 \mathrm{hr}$ when the $\mathrm{pH}$ was 7.8 (see Figure 10).

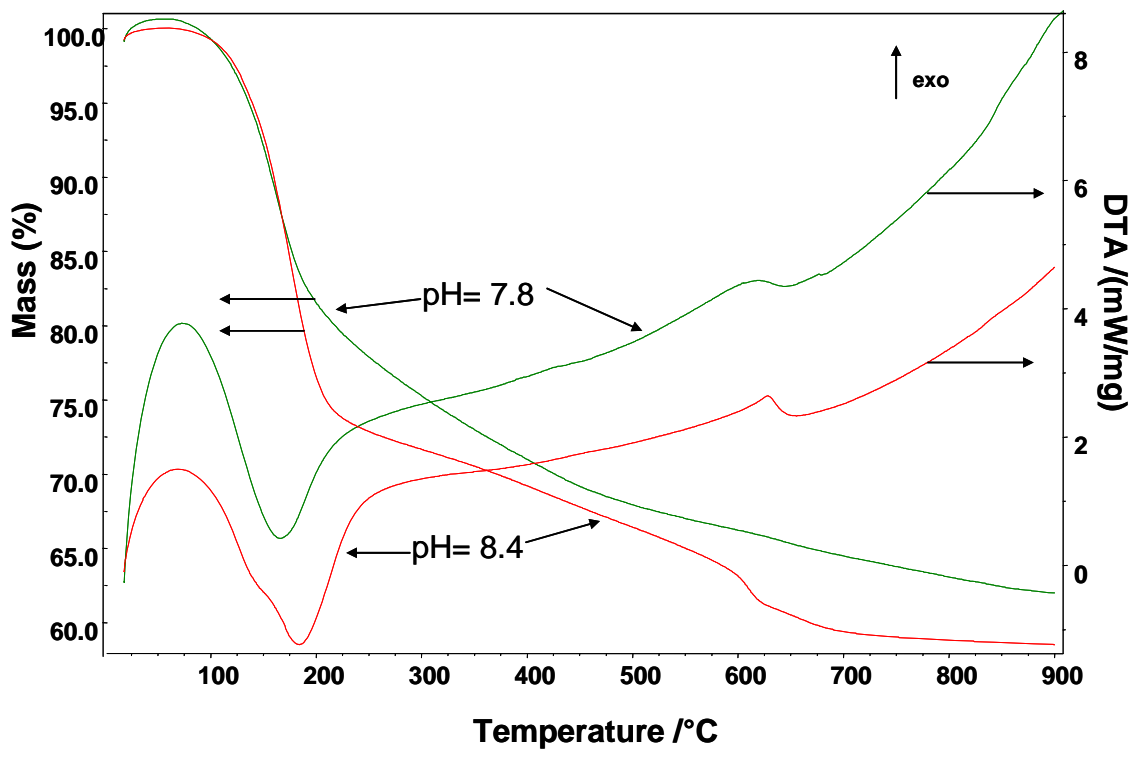


Figure 8. TGA/DTA curves for GSGG precursor powders produced at different $\mathrm{pH}$ values.

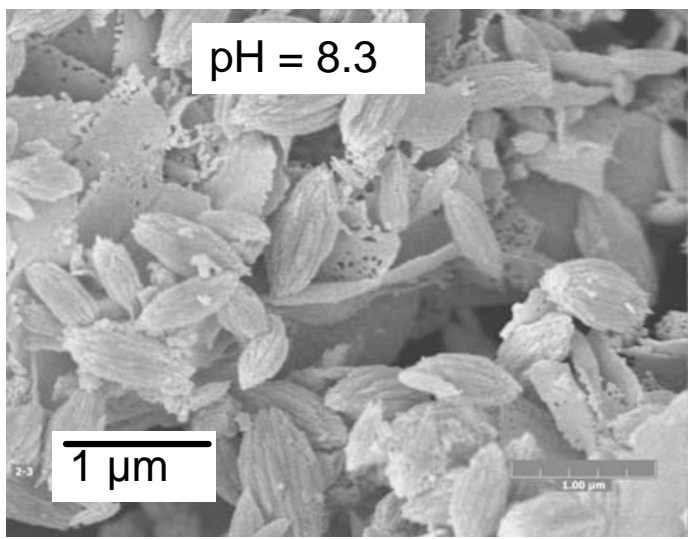

a.

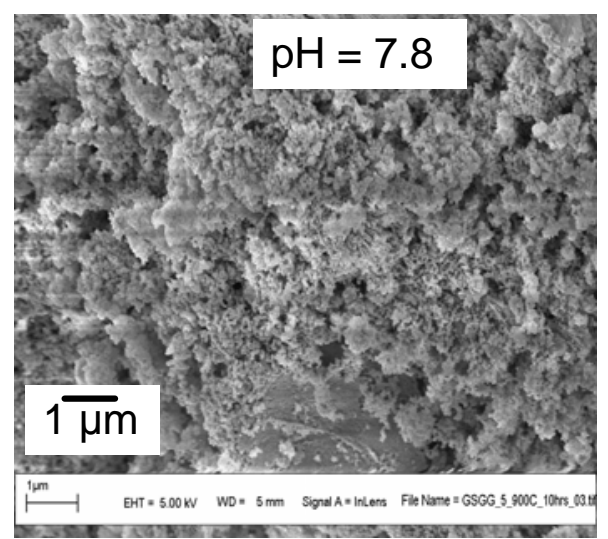

b.

Figure 9. SEM images of GSGG powders produced at pH values of a.) 8.3 and b.) 7.8.

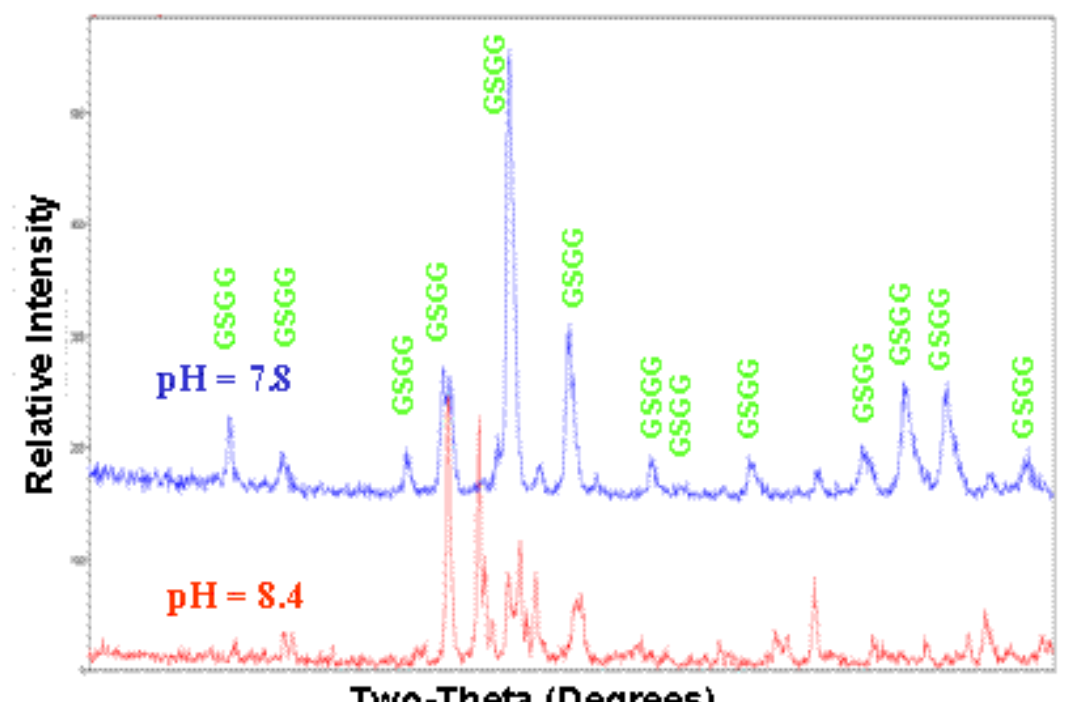

Two-Theta (Degrees)

Figure 10. XRD patterns of calcined GSGG powders synthesized at different $\mathrm{pH}$ values.

The crystallization of the garnet phase from the baseline precursor powder (GSGG-6) was studied using in situ XRD with heating at $25^{\circ} \mathrm{C} / \mathrm{min}$ between $500^{\circ}$ and $1000^{\circ} \mathrm{C}$, with a 10 min hold to take a spectrum every $25^{\circ} \mathrm{C}$. The data, shown in Figure 11, indicate that the crystallization starts around $850^{\circ} \mathrm{C}$. Therefore, powders were calcined at $900^{\circ}$ or $1000^{\circ} \mathrm{C}$, typically for $5 \mathrm{hr}$ to ensure complete crystallization. In some cases, after calcination very minor peaks of other phases, typically $\mathrm{Gd}_{2} \mathrm{O}_{3}$ or $\mathrm{Sc}_{2} \mathrm{O}_{3}$, were found in the XRD patterns of calcined powders but were not present after those powders were sintered. The BET surface area of the calcined baseline powder was $\sim 26 \mathrm{~m}^{2} / \mathrm{g}$, which corresponds to an equivalent spherical diameter of $87 \mathrm{~nm}$. This was consistent with the SEM images (see Figure 12) that showed the powder to consist of particles $<100 \mathrm{~nm}$ in size that formed larger aggregates. These aggregates were broken apart by the ultrasonic milling to give typical average measured particle size in suspension of $\sim 0.3 \mathrm{~m}$. Compacts of the calcined, ultrasonically milled powder made by vacuum 
filtration were uniform and free of large pores or other defects. After cold isostatic pressing, the compacts had a relative green density of $\sim 52 \%$. Figure 13 shows the shift in lattice parameter from $12.38 \AA$ for a calcined GGG powder to $12.58 \AA$ for a baseline GSGG powder.

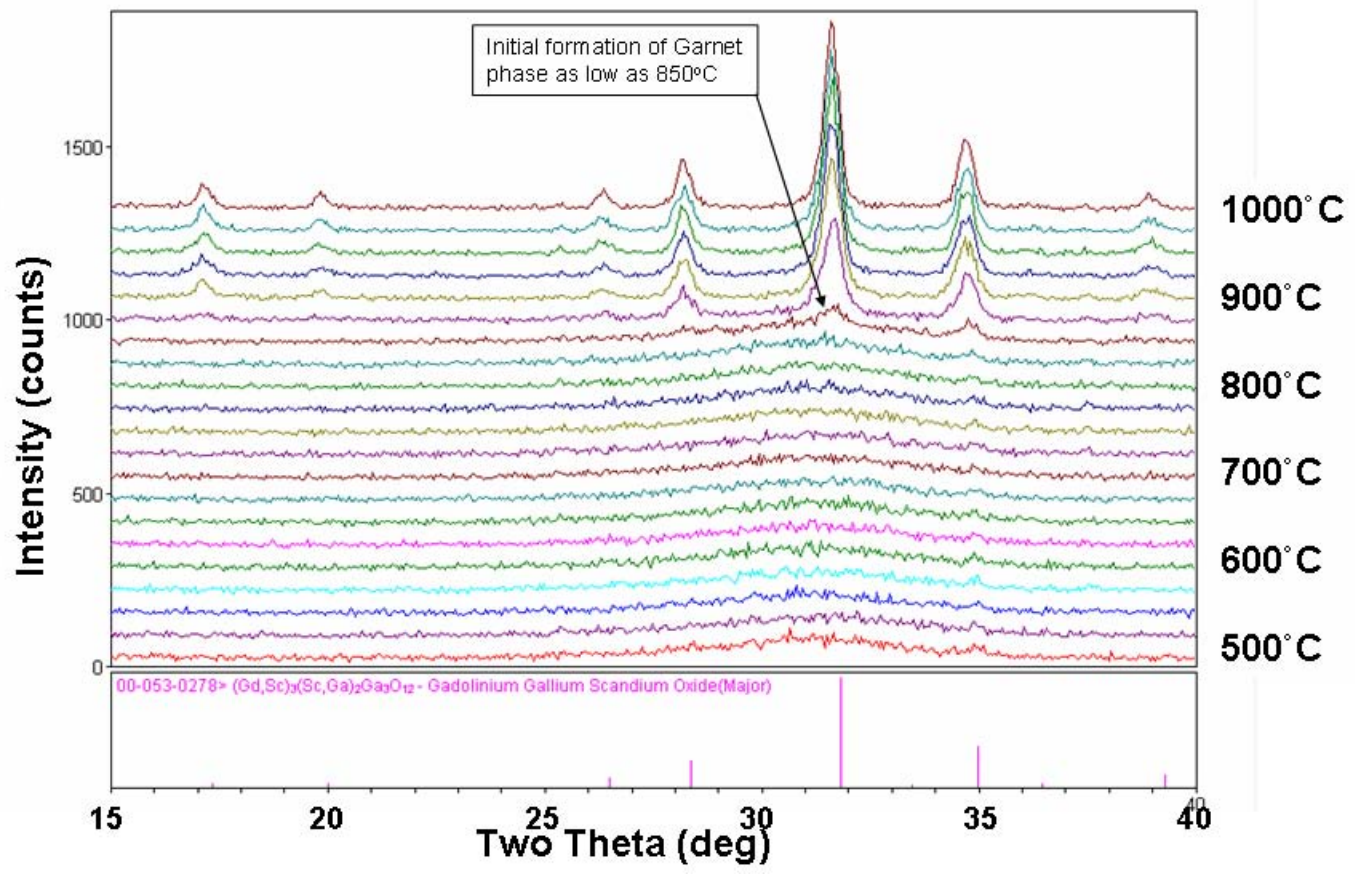

Figure 11. High-temperature XRD results on baseline GSGG precursor powder.
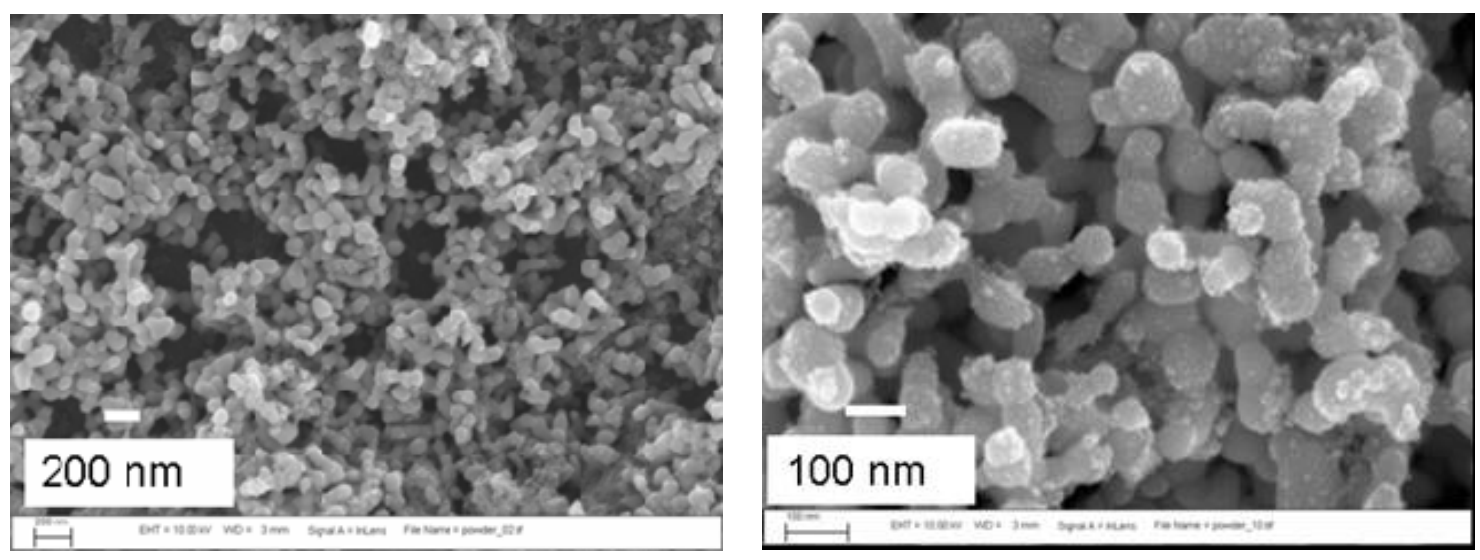

Figure 12. SEM images of calcined GSGG-18 powder. 


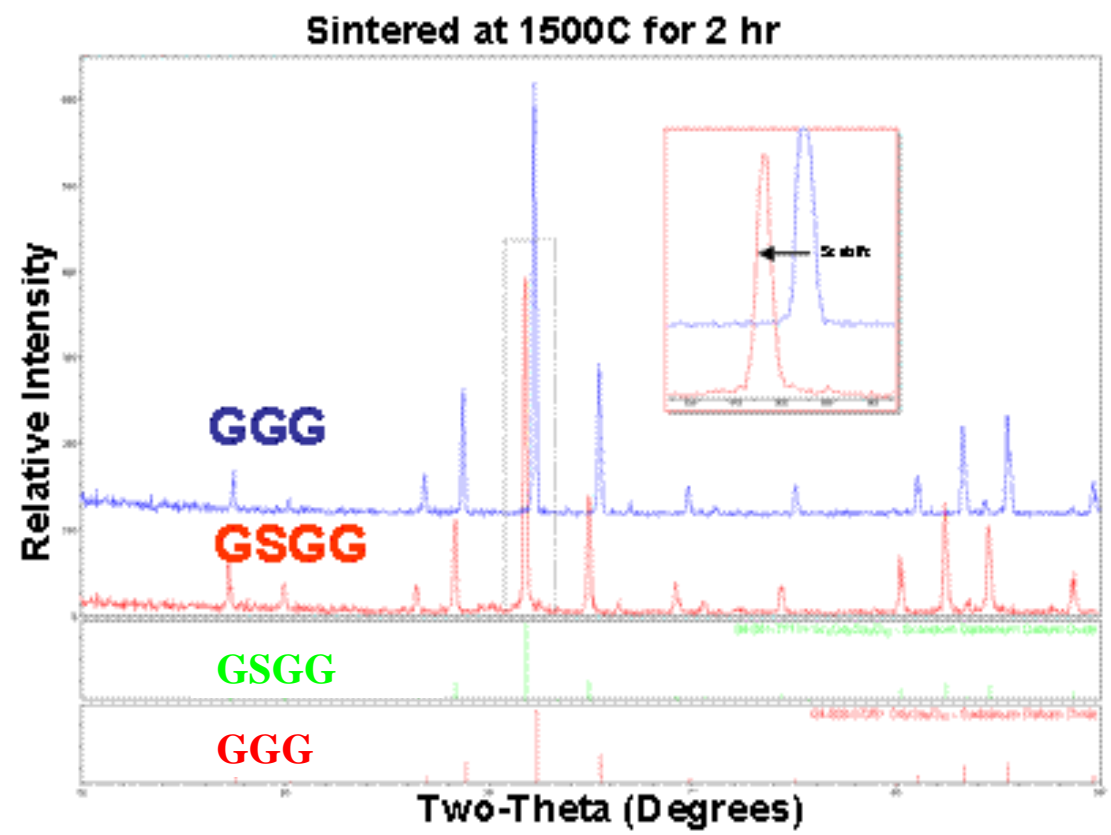

Figure 13. XRD patterns for baseline GGG and GSGG calcined powders showing shift in peaks due to increase in lattice parameter with the presence of Sc.

\section{Nd:YAG Sintering}

The densification behavior of the cold isostatically pressed, vacuum filtration compact of the calcined baseline $\mathrm{Nd}$ :YAG powder is shown in Figure 14 during heating at $10^{\circ} \mathrm{C} / \mathrm{min}$ in rough vacuum. The densification began around $1200^{\circ} \mathrm{C}$ and a density of $90 \%$ was reached by $1450^{\circ} \mathrm{C}$, due to the small size of the particles. Initial samples were sintered in high vacuum in furnace \#1 directly to high temperature, such as $1650^{\circ} \mathrm{C}$, and they were somewhat transparent as shown in Figure 15. Examination of these samples in the SEM revealed that they contained numerous very large pores ( $\sim 30 \mathrm{~m}$ diameter), as shown in Figure 16. At first, it was thought that these pores were the result or either contamination or bubbles in the slurry, but further sintering studies indicated that they formed do to pore collision and growth. For example, when a compact was heated to $1500^{\circ} \mathrm{C}$ for $6 \mathrm{hr}$ (Figure 17), many smaller $(\sim 1 \mathrm{~m})$ pores were present. Although much smaller than the pores found in the higher temperature sintered sample, they were still much larger than the size of the YAG grains $(\sim 0.5 \mathrm{~m})$. Sintering theory predicts that when the dihedral angle is $\sim 120^{\circ}$ (see Figure 18), all pores larger than the grains will grow in size with continued sintering. In other words, more sintering will not decrease the porosity, only redistribute it into fewer, larger pores through mechanisms such as pore collision. 


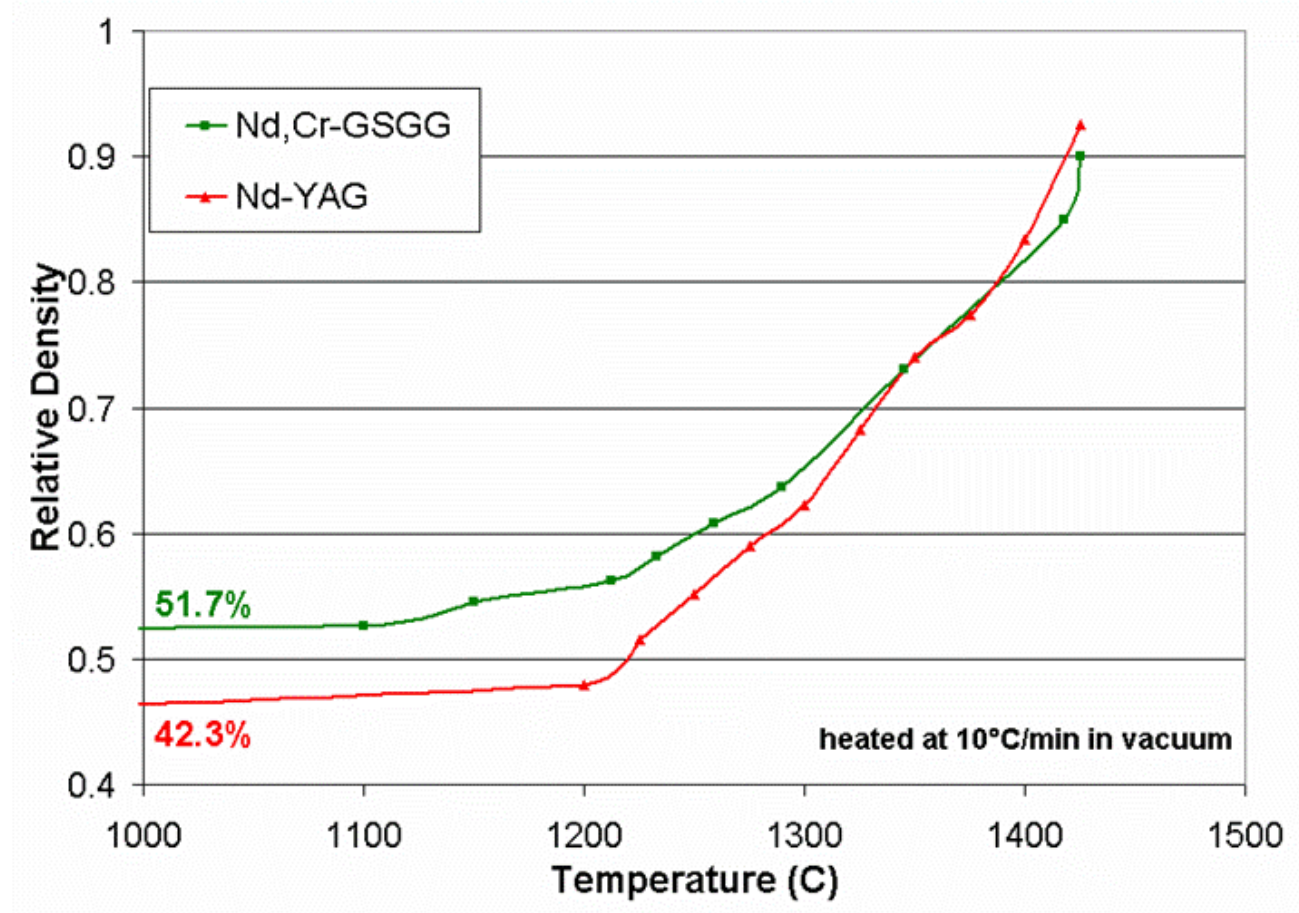

Figure 14. The densification behavior of baseline Nd;YAG and Cr.Nd:GSGG powder compacts.

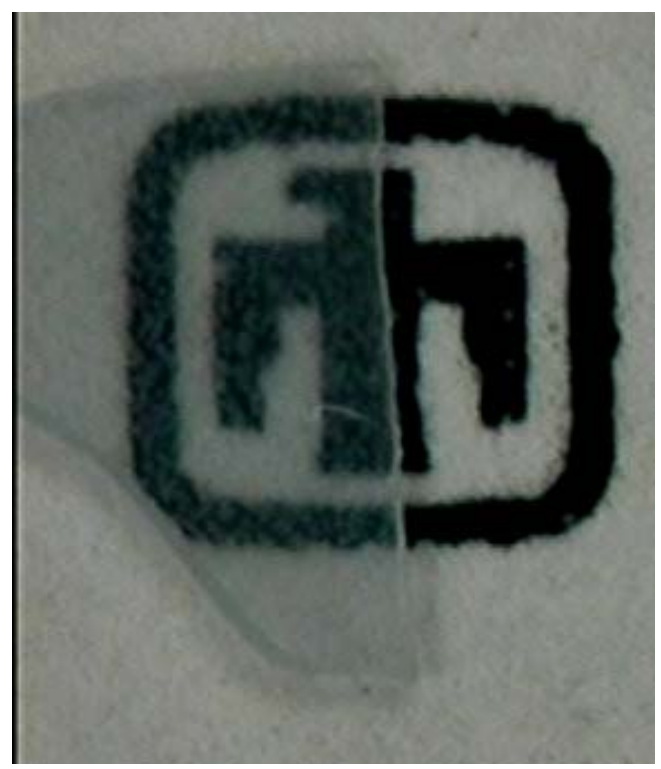

Figure 15. Photograph of YAG sample that was vacuum sintered at $1650^{\circ} \mathrm{C}$ for $5 \mathrm{hr}$. 

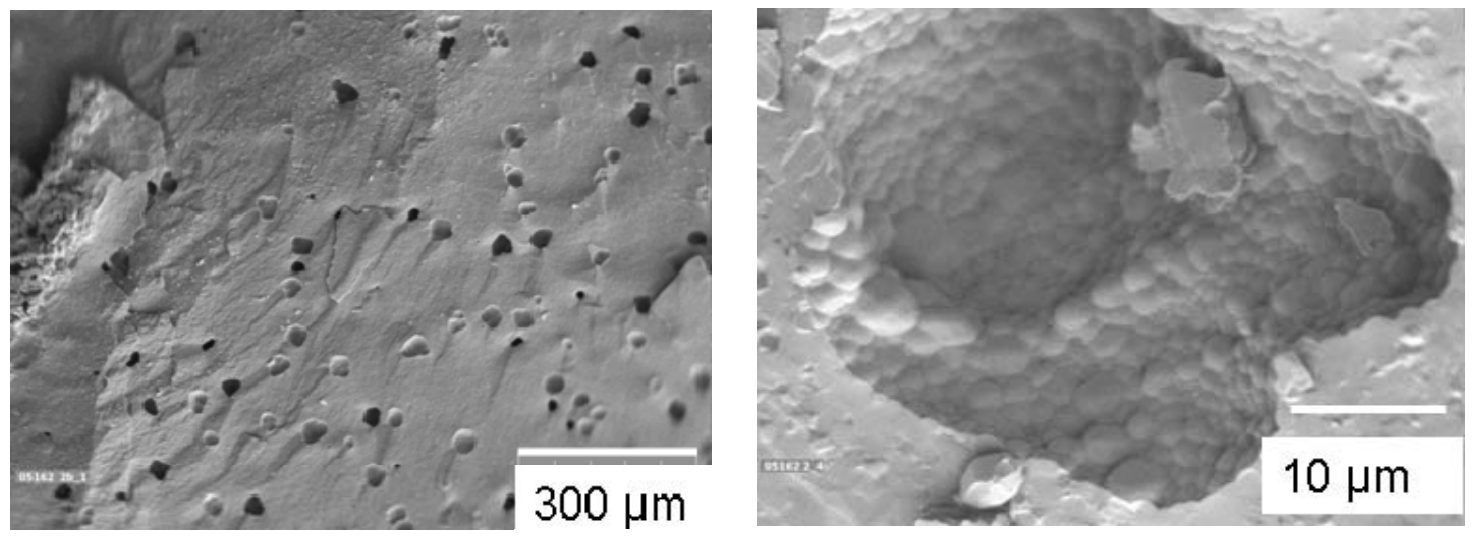

Figure 16. SEM images of the fracture surface of a YAG sample sintered in vacuum at $1700 \mathrm{C}$ for $5 \mathrm{hr}$.

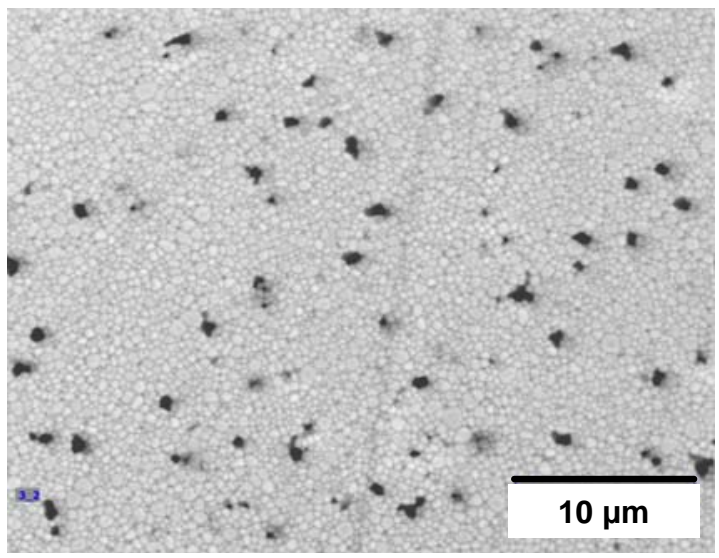

a.

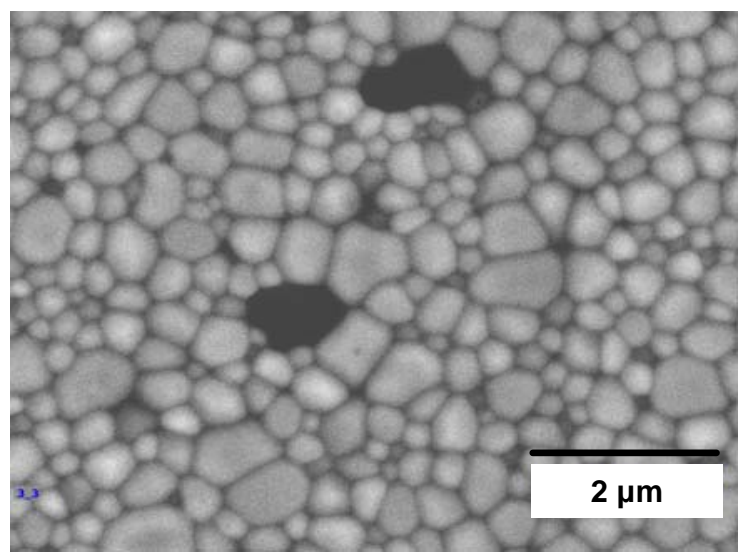

b.

Figure 17. SEM images of a YAG sample sintered at $1500 \mathrm{C}$ for $6 \mathrm{hr}$.

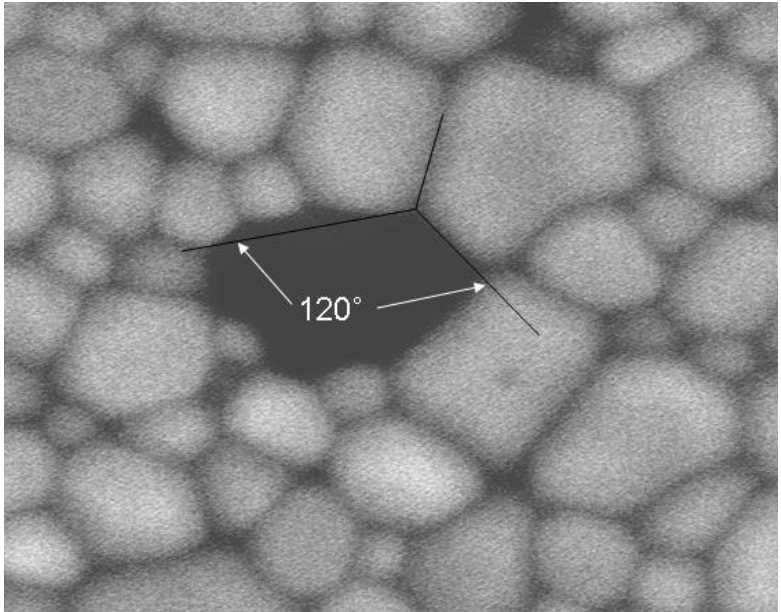

Figure 18. Pore in a sintered YAG sample showing a dihedral angle of $\sim 120$. 
One approach to eliminating large pores was by grain growth to increase the size of the YAG grains until they were larger than the pores. However, if the grain growth is too rapid, the pores can break away from the grain boundaries. Once this occurs, as in the sample shown in Figure 19 that was first sintered at $1500^{\circ} \mathrm{C}$ for $4 \mathrm{hr}$ and then heated to $1800^{\circ} \mathrm{C}$ for $6 \mathrm{hr}$, further sintering will not be able to remove the pores inside the grains. Minimizing the size of the residual pores is a second approach. This was done by lowering the initial soak temperature. At a lower temperature, the densification rate is lower and relative rates of coarsening mechanisms, such as surface diffusion, are higher and these prevent pore growth resulting in residual pores smaller than the grain size. For example, Figure 20 shows a sample first heated to $1400^{\circ} \mathrm{C}$ in vacuum for $1 \mathrm{hr}$ and before heating to $1500^{\circ} \mathrm{C}$ for $6 \mathrm{hr}$. Note that the pores are much smaller than in the sample in Fig $\mathrm{x}$ that was heated directly to $1500^{\circ} \mathrm{C}$ for $6 \mathrm{hr}$. Using this two-stage sintering approach, samples with essentially theoretical density (to the accuracy of the Archimedes method) were produced (see Table 3). However, these samples were not transparent.

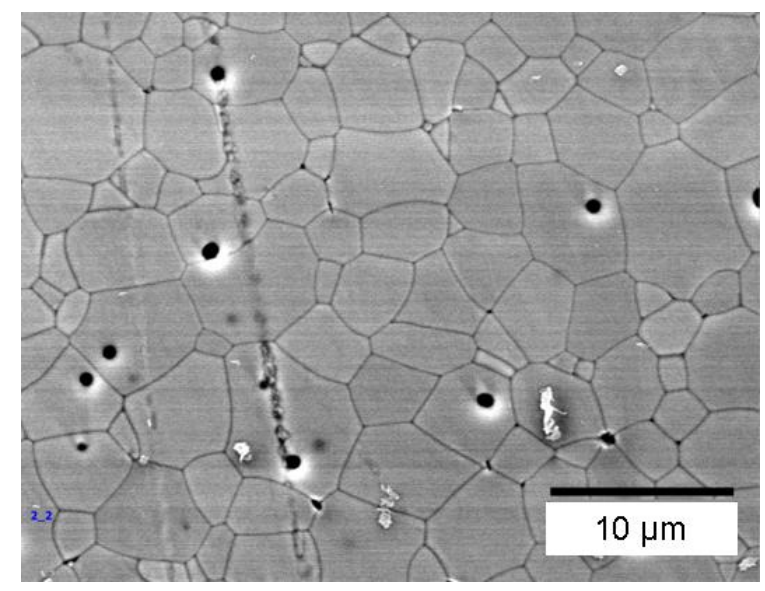

Figure 19. YAG sample first heated to $1500 \mathrm{C}$ for $4 \mathrm{hr}$ and then to $1800 \mathrm{C}$ for $6 \mathrm{hr}$.

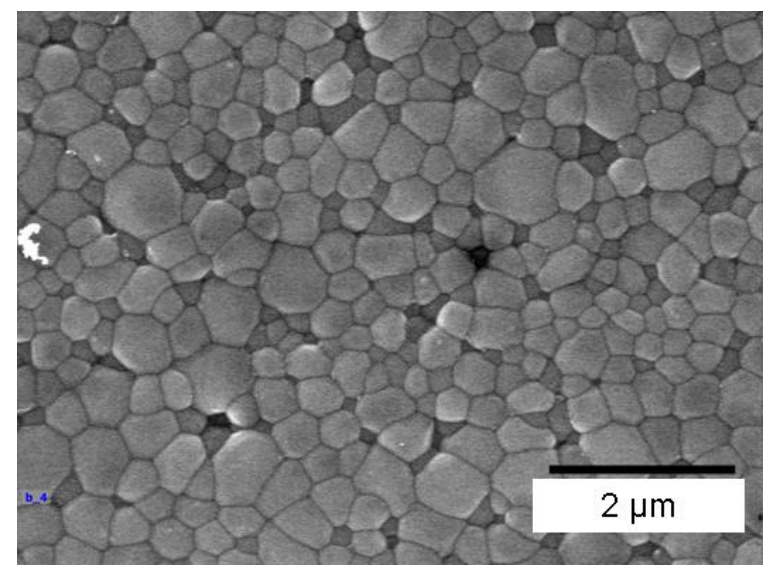

Figure 20. YAG sample first heated to $1400 \mathrm{C}$ for $1 \mathrm{hr}$ and then to $1500 \mathrm{C}$ for $6 \mathrm{hr}$. 
Table 3. Sintered densities of YAG-26 samples.

\begin{tabular}{|c|c|}
\hline Sintering Schedule & Final Density $\left(\mathrm{g} / \mathrm{cm}^{3}\right)$ \\
\hline $1425^{\circ} \mathrm{C}$ for $1 \mathrm{hr}(\mathrm{vac})$ & 4.45 \\
\hline $1425^{\circ} \mathrm{C}$ for $1 \mathrm{hr}$ (vac) followed by $1600^{\circ} \mathrm{C}$ for $6 \mathrm{hr}$ (air) & 4.56 \\
\hline $1600^{\circ} \mathrm{C}$ for $6 \mathrm{hr}$ (air) & 4.47 \\
\hline $1425^{\circ} \mathrm{C}$ for $1 \mathrm{hr}$ (vac) followed by $1700^{\circ} \mathrm{C}$ for $3 \mathrm{hr}$ (air) & 4.55 \\
\hline $1700^{\circ} \mathrm{C}$ for $3 \mathrm{hr}$ (air) & 4.47 \\
\hline
\end{tabular}

One reason that the high density sintered samples were not transparent was the presence of second phase particles. For example, Figure 21 shows that even though powder from a stoichiometric batch (\#11) was single phase garnet by XRD after calcination, a second phase, $\mathrm{YAlO}_{3}$, was detected by XRD after high temperature sintering. The inset shows an optical micrograph of the large second phase inclusions. Because of the nearness in stoichiometry of the YAG and $\mathrm{YAlO}_{3}$, only a slight amount of excess $\mathrm{Y}$ can lead to a much larger amount of the $\mathrm{YAlO}_{3}$ phase. It was for this reason that batches 24 to 26 were produced with excess Al. The amount of excess $\mathrm{Al}$ added was based on semi-quantitative XRD results. To try to confirm whether 5\% excess $\mathrm{Al}$ was the required amount, this amount was added to some calcined YAG12 powder using aluminum nitrate solution. After calcining and sintering, this material was single phase garnet by XRD. Therefore this amount, 5\%, was used to make batches 24 and 25. Although single phase garnet by slow scan XRD after calcination, when compacts from the $\mathrm{Al}$ excess batches were sintered, they were found to have second phase alumina particles, both by XRD and by SEM (see Figure 22). The sample shown in the figure was of batch 25 (5\% excess $\mathrm{Al}$ ) that was sintered at $1400^{\circ} \mathrm{C}$ for $1 \mathrm{hr}$ in rough vacuum then at $1650^{\circ} \mathrm{C}$ for $2 \mathrm{hr}$ in air. As can be seen in the micrographs, porosity of the sample was quite low so that the alumina was most likely the main scattering source. Some experiments were then performed using powder from batch 25 to determine how much Y needed to be added to reach the desired stoichiometry. Yttrium was added to the powder using yttrium nitrate solution, drying and then recalcining the powder. Increments of $0.1 \% \mathrm{Y}$ were used and the calcined powders were dry pressed and sintered. Optical microcopy on the samples indicated that the one with $1 \%$ Y added had $\mathrm{YAlO}_{3}$ particles while the one with $0.9 \%$ did not (see Figure 23 ). When a sample with this same composition was made into a 1" diameter vacuum filtered compact and then uniaxially hotpressed at $1450^{\circ} \mathrm{C}$ for $2 \mathrm{hr}$ at $6 \mathrm{ksi}$ pressure using Mo spacer disks, a relatively transparent sample was produced (see Figure 24 where the sample covers the left part of the text). The reason for the dark ring on the sample is not known. 


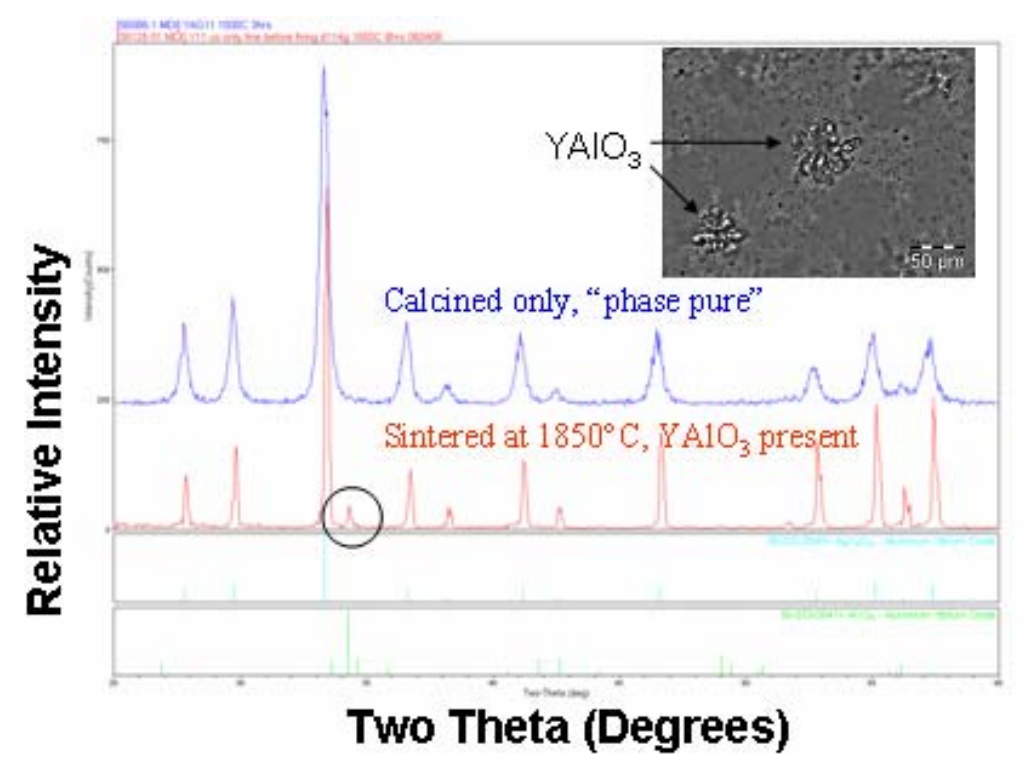

Figure 21. XRD patterns of a stoichiometric Nd:YAG batch (\#11) that indicate $\mathrm{YAlO}_{3}$ after sintering.
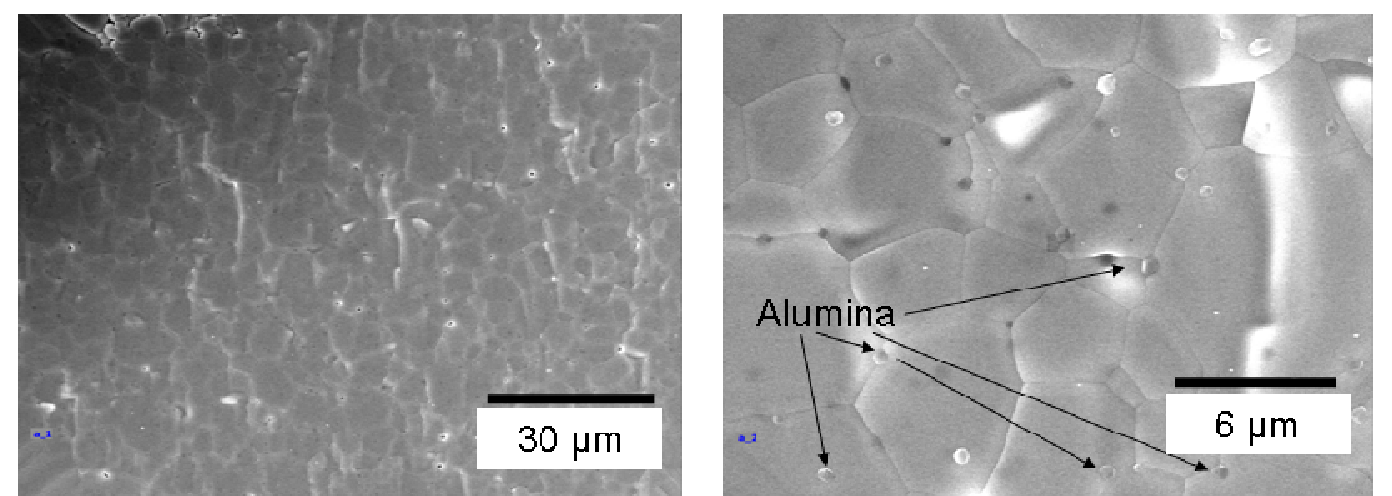

Figure 22. SEMs of a sintered Nd:YAG powder with excess Al (batch 25) showing the presence of alumina.

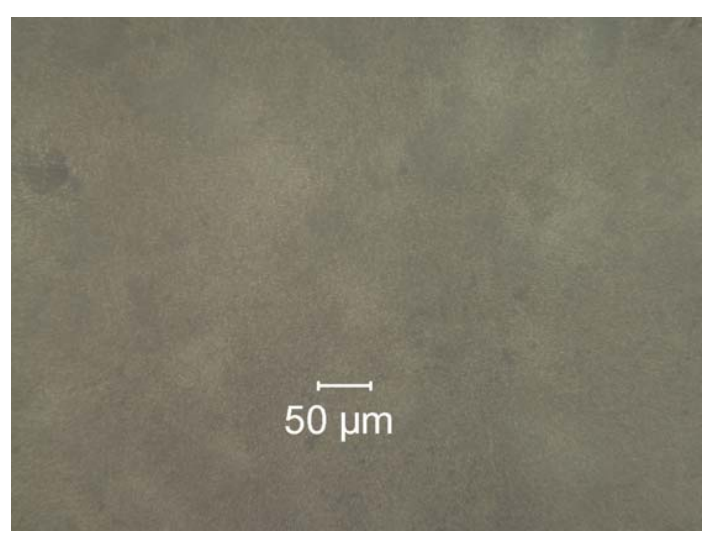

a.

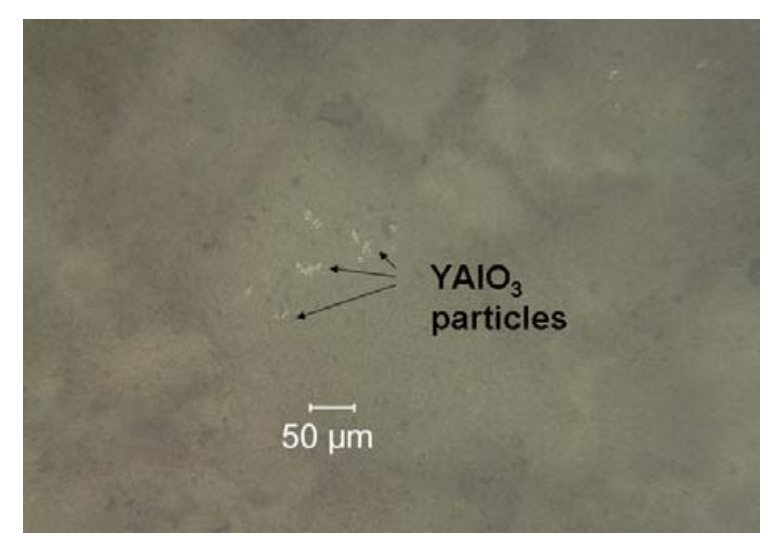

b.

Figure 23. Sintered samples of YAG-25 (5\% xs Al) to which Y was added, a.) $0.9 \% \mathrm{Y}$ and b.) $1.0 \% \mathrm{Y}$. 


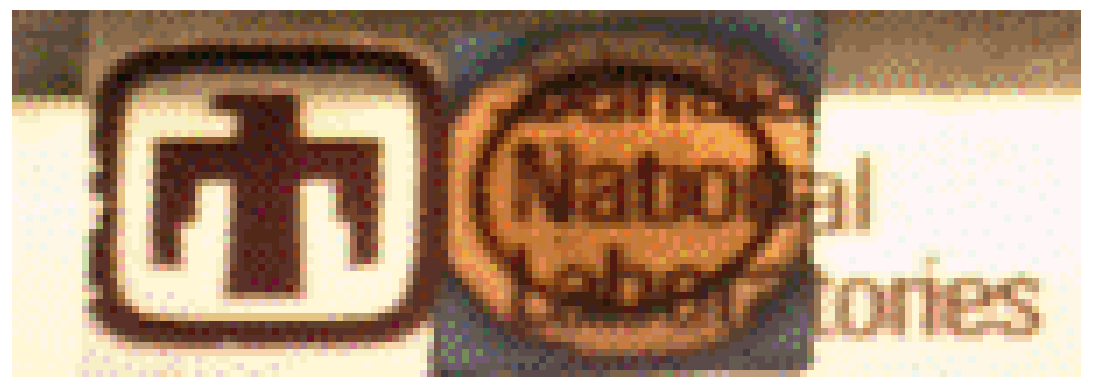

Figure 24. Hot-pressed sample of YAG-25 + 0.9\%Y (1450 C for $2 \mathrm{hr}$ at $6 \mathrm{ksi})$.

\section{Cr,Nd:GSGG Sintering}

The densification behavior of the baseline Cr,Nd:GSGG powder was quite similar to that of the $\mathrm{Nd}$;YAG powder, although the green density was higher, 52\%, for the GSGG (see Figure 14). Densification began around $1200^{\circ} \mathrm{C}$ and density of $\sim 90 \%$ of theoretical was reached by $1450^{\circ} \mathrm{C}$ with $10^{\circ} \mathrm{C} / \mathrm{min}$ heating in vacuum. When compacts from the first $9 \mathrm{~g}$ batches of $\mathrm{Cr}, \mathrm{Nd}$ :GSGG powder were sintered, they reached high density (see Table 4.). They were green in color as expected due to the presence of $\mathrm{Cr}^{3+}$. In fact, the measured density was higher than the single crystal density for the desired composition $\left(6.45 \mathrm{~g} / \mathrm{cm}^{3}\right)$. A sample of GSGG-7 reached a density of $6.62 \mathrm{~g} / \mathrm{cm}^{3}$ after only $2 \mathrm{hr}$ at $1425^{\circ} \mathrm{C}$. Resintering that sample at $1600^{\circ} \mathrm{C}$ did not increase its density but a sample heated directly to $1600^{\circ} \mathrm{C}$ for $6 \mathrm{hr}$ in air reached a slightly higher density. The higher than theoretical density suggested that the stoichiometry of the material was slightly Gd-rich, since Gd is by far the heaviest element present. SEMs of a sintered GSGG-7 sample (Figure 25) showed the presence to second phase precipitates, consistent with the stoichiometry being off. Scandium-deficiency was also suspected in batches 6 and 7 since the filtrate from the powder synthesis, when dried and ashed, contained scandium oxide. Based on these results, the next three batches were synthesized with $2 \%$ deficiency in $\mathrm{Gd}$.

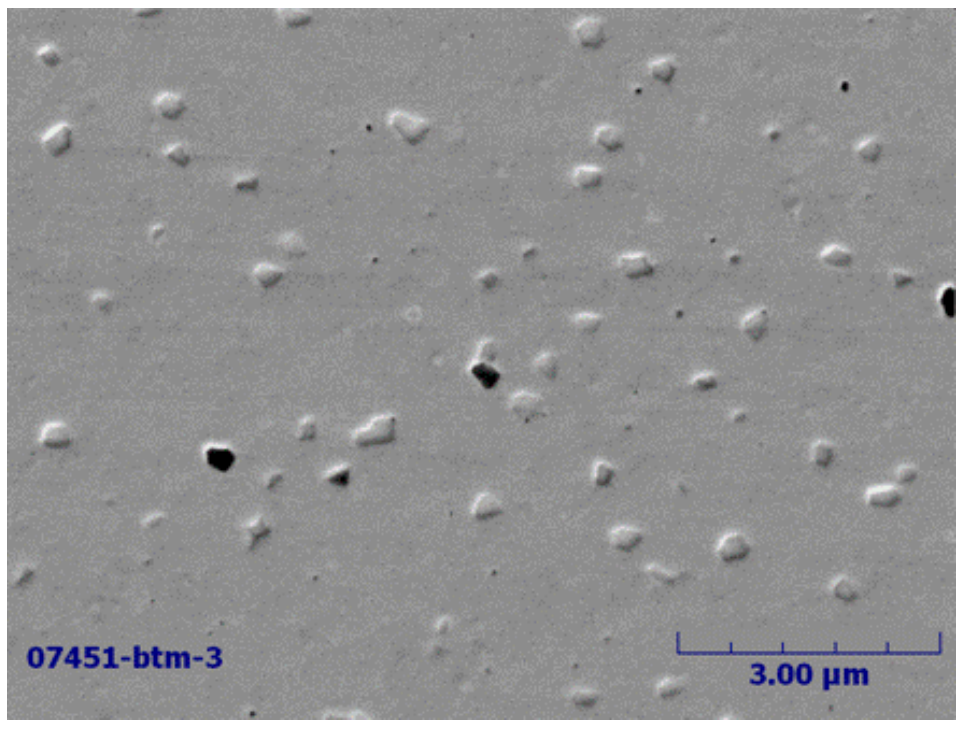

Figure 25. SEM image of a sintered GSGG-7 powder (1450 C for $1 \mathrm{hr}$ in vacuum) showing second phase particles. 
Table 4. Summary of sintering results on various Cr.Nd:GSGG samples.

\begin{tabular}{|c|c|c|}
\hline $\begin{array}{l}\text { GSGG } \\
\text { batch \# }\end{array}$ & Sintering Conditions & $\begin{array}{l}\text { Density } \\
\left(\mathrm{g} / \mathrm{cm}^{3}\right)\end{array}$ \\
\hline 7 & $1425^{\circ} \mathrm{C}$ for $2 \mathrm{hr}(\mathrm{vac})$ & 6.62 \\
\hline 7 & $1425^{\circ} \mathrm{C}$ for $2 \mathrm{hr}(\mathrm{vac})+1600^{\circ} \mathrm{C} 6 \mathrm{hr}$ (air) & 6.60 \\
\hline 7 & $1600^{\circ} \mathrm{C} 6 \mathrm{hr}$ (air) & 6.66 \\
\hline 12 & $1450^{\circ} \mathrm{C}$ for $2 \mathrm{hr}(\mathrm{vac})$ & 6.11 \\
\hline 12 & $1450^{\circ} \mathrm{C}$ for $2 \mathrm{hr}(\mathrm{vac})+1450^{\circ}$ and $1500^{\circ} \mathrm{C}$ for $15 \mathrm{hr}$ each (air) & 6.48 \\
\hline 12 & $\begin{array}{l}1450^{\circ} \mathrm{C} \text { for } 2 \mathrm{hr}(\mathrm{vac})+1450^{\circ}, 1500^{\circ} \text { and } 1550^{\circ} \mathrm{C} \text { for } 15 \mathrm{hr} \text { ea. } \\
\text { (air) }\end{array}$ & 6.49 \\
\hline 13 & $1450^{\circ} \mathrm{C}$ for $2 \mathrm{hr}(\mathrm{vac})$ & 6.11 \\
\hline 13 & $1450^{\circ} \mathrm{C}$ for $2 \mathrm{hr}(\mathrm{vac})+1550^{\circ} \mathrm{C}$ for $5 \mathrm{hr}$ (air) & 6.37 \\
\hline 17 & $1500^{\circ} \mathrm{C}$ for $2 \mathrm{hr}(\mathrm{vac})$ & 6.30 \\
\hline 17 & $1500^{\circ} \mathrm{C}$ for $2 \mathrm{hr}(\mathrm{vac})+1500^{\circ} \mathrm{C}$ for $80 \mathrm{hr}$ (air) & 6.31 \\
\hline 18 & $1500^{\circ} \mathrm{C}$ for $2 \mathrm{hr}(\mathrm{vac})$ & 6.28 \\
\hline 18 & $1500^{\circ} \mathrm{C}$ for $2 \mathrm{hr}(\mathrm{vac})+1600^{\circ} \mathrm{C}$ for $2 \mathrm{hr}$ (air) & 6.29 \\
\hline 22 & $1450^{\circ} \mathrm{C}$ for $2 \mathrm{hr}(\mathrm{vac})$ & 6.18 \\
\hline 22 & $1450^{\circ} \mathrm{C}$ for $2 \mathrm{hr}(\mathrm{vac})+1550^{\circ} \mathrm{C}$ for $15 \mathrm{hr}$ (air) & 6.33 \\
\hline 22 & $\begin{array}{l}1450^{\circ} \mathrm{C} \text { for } 2 \mathrm{hr}(\mathrm{vac})+1550^{\circ} \mathrm{C} \text { for } 15 \mathrm{hr}(\text { air })+1575^{\circ}, 1600^{\circ} \\
\text { and } 1625^{\circ} \mathrm{C} \text { for } 5 \mathrm{hr} \text { each (air) }\end{array}$ & 6.33 \\
\hline
\end{tabular}

When a compact from batch 10 was sintered at $1425^{\circ} \mathrm{C}$ for $2 \mathrm{hr}$ in rough vacuum and then at $1575^{\circ} \mathrm{C}$ for 30 minutes in air, a high density, essentially pore-free microstructure with fine grains ( $\sim 0.5 \mathrm{~m}$ average) was obtained (see Figure 26$)$. However, the sample was not transparent, but somewhat translucent. Table 12 shows that the density of a sample from batch 12, also with $2 \%$ Gd deficiency, reached $6.11 \mathrm{~g} / \mathrm{cm}^{3}$ after $2 \mathrm{hr}$ at $1450^{\circ} \mathrm{C}$ in vacuum and increased to $6.48 \mathrm{~g} / \mathrm{cm}^{3}$ after $15 \mathrm{hrs}$ at both $1450^{\circ}$ and then $1500^{\circ} \mathrm{C}$ in air. The density of this sample increased only to $6.49 \mathrm{~g} / \mathrm{cm}^{3}$ after an additional $15 \mathrm{hr}$ at $1550^{\circ} \mathrm{C}$. These densities were still higher than the theoretical value. Figure 27 shows that, similar to what was found for the YAG materials, large pores formed when the sintering was done by heating directly to high temperature $\left(1700^{\circ} \mathrm{C}\right)$. 

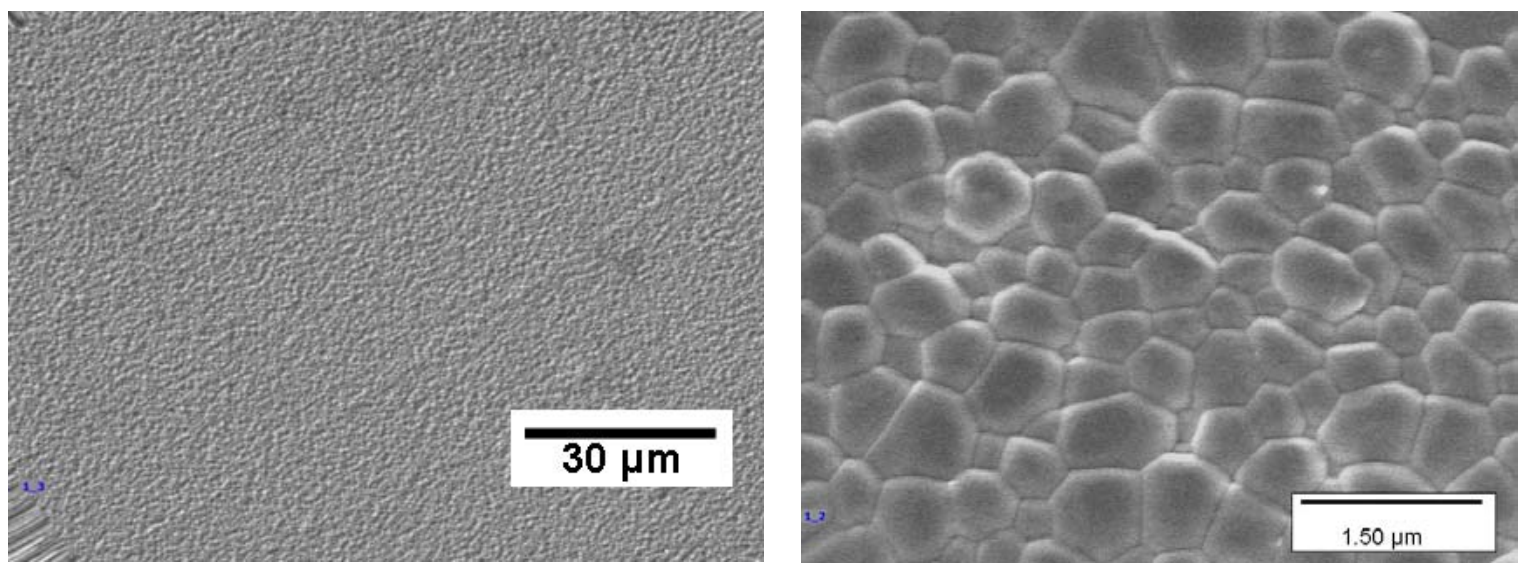

Figure 26. SEM images of GSGG-10 sintered at 1425 C for $2 \mathrm{hr}(\mathrm{vac})$ then at $1575 \mathrm{C}$ for 30 $\min ($ air).

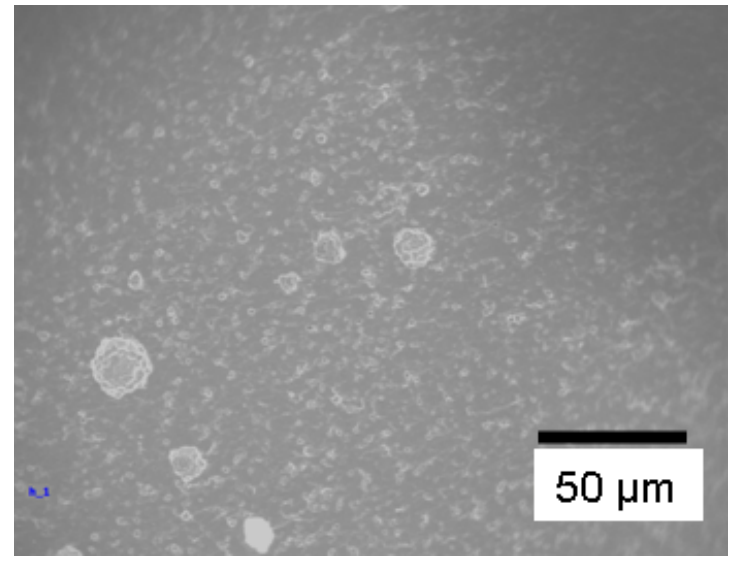

a.

Figure 27. GSGG sintered at high temperature (1700

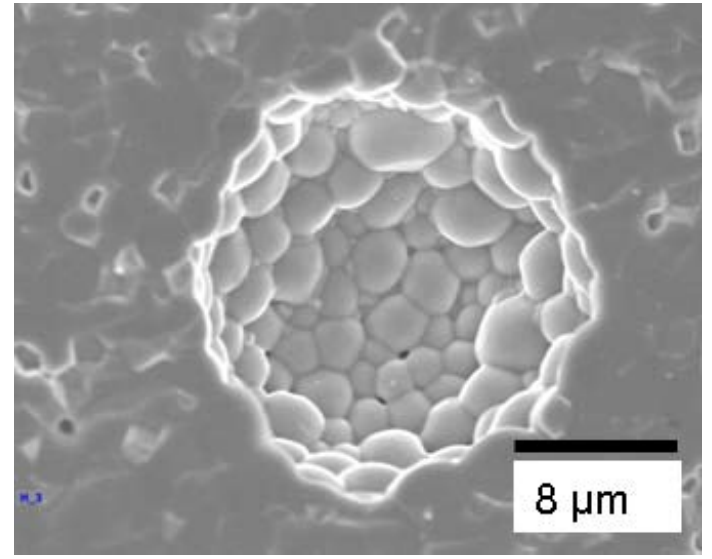

b.

A compact $\left(0.5 \%\right.$ die) of GSGG-10 was hot-pressed at $1250^{\circ} \mathrm{C}$ for 75 min at $6 \mathrm{ksi}$ using Pt spacers. After hot-pressing, the sample $(\sim 1 \mathrm{~mm}$ thick $)$ was dark but slightly transparent in the central region and white and opaque in a region around the edge, several $\mathrm{mm}$ wide. This white region was later found by microprobe analysis to be devoid of $\mathrm{Ga}$, due to vaporization in the low $\mathrm{pO}_{2}$ atmosphere inside the hot-press. In air, the mass loss of GSGG samples was negligible up to $1650^{\circ} \mathrm{C}$. Annealing the sample in air at $1250^{\circ} \mathrm{C}$ for $1 \mathrm{hr}$ changed the interior to green but did not greatly increase the transparency, according to the uv-vis spectra, from $0 \%$ at $460 \mathrm{~nm}$ and below to $\sim 15 \%$ at $850 \mathrm{~nm}$. Adsorption bands were seen in the expected regions $(\sim 590 \mathrm{~nm}, \sim 750 \mathrm{~nm}$ and $\sim 800 \mathrm{~nm}$ ). The overall shape of the transmission spectra was typical of a material that still contained scattering centers of some type. When the sample was annealed at $1350^{\circ} \mathrm{C}$ it became translucent. SEM examination revealed that grain growth had occurred but did not reveal any cause for the increased opacity (Figure 28). 


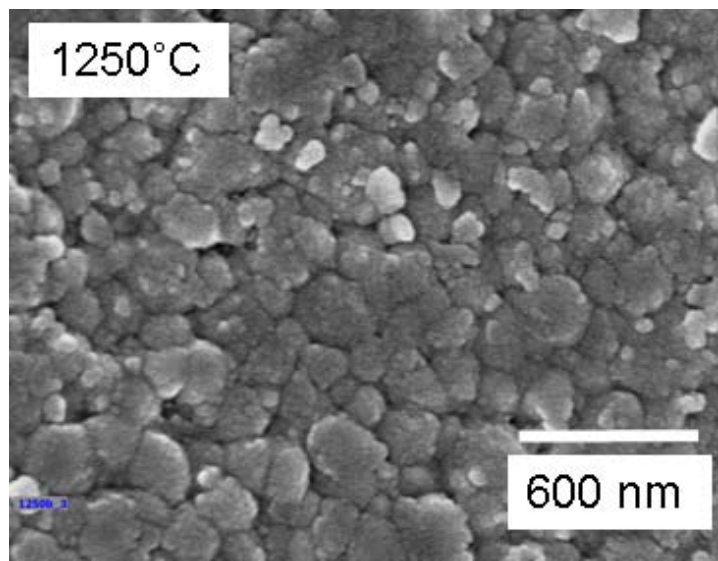

a.

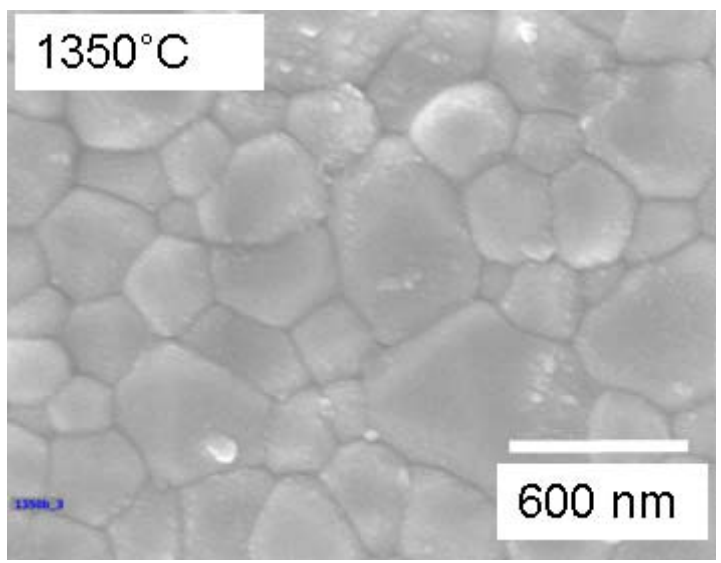

b.

Figure 28. SEM images of a hot-pressed GSGG-10 sample after air annealing for $1 \mathrm{hr}$ at a.) $1250 \mathrm{C}$ and b.) $1350 \mathrm{C}$.

At this point, to further check the stoichiometry of the GSGG materials, quantitative microprobe analysis was performed (see Table 5). The first samples analyzed (Group 1) were a commercial single crystal (grown by Litton Corp., now part of Northrup Grumman, Baltimore, MD) and a sintered GSGG-10 sample. The composition found for the single crystal was close to the desired composition (shown in the first line of Table 5), but was slightly Ga-rich and Sc and Gd-poor. On the other hand, GSGG-10 was found to be quite low in Sc, with only $11.5 \%$ (as wt\% oxide) detected as opposed to the desired $14.5 \%$. The Gd content was also somewhat higher than desired. The $\mathrm{Nd}$ and $\mathrm{Cr}$ were also detected and found to be close to their targets. Also, samples were hot-pressed of GSGG-11 to which $3 \mathrm{wt} \%$ additional $\mathrm{Sc}_{2} \mathrm{O}_{3}$ was added (by soaking the bisque-fired compact in a scandium nitrate solution) were found to be more transparent than the hot-pressed GSGG-10 sample, with the some transmission down to $\sim 300 \mathrm{~nm}$ and increasing to $\sim 40 \%$ at $800 \mathrm{~nm}$. Based on these results, the target synthesis composition was once again changed to try to increase the Sc content and decrease that of the Gd (see Table 2). Also, batch 13 was prepared without $\mathrm{Cr}$ to see if the $\mathrm{Cr}$ was affecting the transparency of the samples.

When a sample of GSGG-13 was sintered at $1450^{\circ} \mathrm{C}$ for $2 \mathrm{hr}$ in rough vacuum and then at $1550^{\circ} \mathrm{C}$ for $5 \mathrm{hr}$ in air, a density of $6.37 \mathrm{~g} / \mathrm{cm}^{3}$ was reached, which is significantly below the theoretical value (Table 4). However, when a compact of GSGG-13 was hot-pressed, it was relatively transparent (see Figure 29). Also, sintered samples of both GSGG-13 and 14 were analyzed using microprobe, and were initially both found to be very close in composition to the single crystal and to the desired composition (see Table 5, Group 2). Therefore, all the remaining batches, except for the last one (GSGG-22), were made using the composition of batch 14 . When compacts from these batches were sintered, they reached only $\sim 6.3 \mathrm{~g} / \mathrm{cm}^{3}$ after 2 $\mathrm{hr}$ in vacuum at $1500^{\circ} \mathrm{C}$, and minimal increase in density occurred with either heating longer at $1500^{\circ} \mathrm{C}$ or heating to higher temperature (see Table 4). Again, the sintered compacts were translucent and green.

Other compacts from batches 13 to 21 were hot-pressed with variable degrees of transparency, but none were laser host quality. Typical densities were similar to those achieved by sintering, although a sample of GSGG-19 that was hot-pressed in a 1 inch die at $1350^{\circ} \mathrm{C}$ for $2 \mathrm{hr}$ reached a density of $6.45 \mathrm{~g} / \mathrm{cm}^{3}$. Loss of $\mathrm{Ga}$ from the compacts during hot-pressing was decreased 
significantly by filling the gap $(\sim 1-2 \mathrm{~mm})$ between the compact and the die wall with coarse GSGG powder prior to pressing. Samples pressed at $1300^{\circ} \mathrm{C}$ or higher using Pt spacers tended to crack, sometimes into small pieces, but those with Mo spacers did not. No significant gain in transparency was achieved by increasing the hot-pressing temperature from $1250^{\circ} \mathrm{C}$ to $1350^{\circ} \mathrm{C}$.

Table 5. Summary of Microprobe results on Cr,Nd:GSGG samples.

\begin{tabular}{|l|l|l|l|l|l|}
\hline Sample & $\begin{array}{l}\mathbf{G d}_{2} \mathbf{O}_{3} \\
(\mathbf{w t} \%)\end{array}$ & $\begin{array}{l}\mathbf{G a}_{2} \mathbf{O}_{3} \\
(\mathbf{w t} \%)\end{array}$ & $\begin{array}{l}\mathbf{S c}_{2} \mathbf{O}_{3} \\
(\mathbf{w t} \%)\end{array}$ & $\begin{array}{l}\mathbf{N d}_{2} \mathbf{O}_{3} \\
(\mathbf{w t} \mathbf{p}\end{array}$ & $\begin{array}{l}\mathbf{C r}_{2} \mathbf{O}_{3} \\
(\mathbf{w t} \%)\end{array}$ \\
\hline $\mathrm{Gd}_{2.95} \mathrm{Ga}_{3} \mathrm{Sc}_{1.95} \mathrm{Nd}_{0.05} \mathrm{Cr}_{0.025} \mathrm{O}_{12}$ & 55.6 & 29.2 & 14.5 & 0.87 & 0.20 \\
\hline Group 1: & & & & & \\
\hline Litton Crystal & 55.2 & 29.8 & 13.7 & 1.11 & 0.14 \\
\hline GSGG-10, sintered & 57.1 & 30.2 & 11.5 & 0.93 & 0.14 \\
\hline Group 2: & & & & & \\
\hline GSGG-13, sintered & 55.0 & 30.2 & 13.8 & 1.08 & 0.00 \\
\hline GSGG-14, sintered & 54.2 & 31.3 & 13.1 & 1.03 & 0.17 \\
\hline Group 3: & & & & & \\
\hline GSGG-7, sintered & 58.6 & 30.4 & 9.9 & 0.95 & 0.15 \\
\hline GSGG-10, sintered, repeat & 57.3 & 30.1 & 11.6 & 0.94 & 0.15 \\
\hline GSGG-14, sintered, repeat & 52.1 & 28.3 & 18.5 & 0.93 & 0.18 \\
\hline GSGG-16, Uni. Hot-Pressed & 53.8 & 28.5 & 16.6 & 0.98 & 0.17 \\
\hline
\end{tabular}

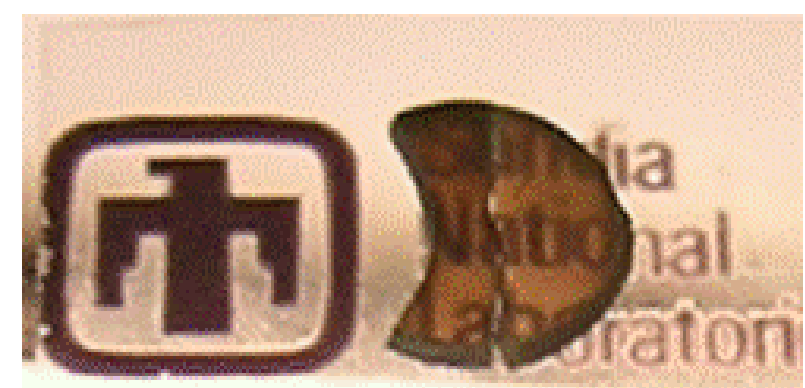

Figure 29. A hot-pressed sample of GSGG-13.

At this point, a third group of samples were analyzed using microprobe (see Table 5). These included a GSGG-7 sample (synthesized with the initial target stoichiometry) that analysis showed was indeed quite low in $\mathrm{Sc}$ and rich in $\mathrm{Gd}$, as was previously concluded. Also, another GSGG-10 sample was analyzed and the results matched the earlier GSGG-10 sample nearly identically. However, when another GSGG-14 was analyzed, it was found to be quite rich in Sc and Gd-deficient, as opposed to the earlier analysis that found the composition to be close to the target. A similar result was found for a hot-pressed GSGG-16 sample. Even though these powders were found to be single phase by XRD after calcination (see Figure 30 for GSGG-15) and even after hot-pressing (see Figure 31 for the same GSGG-16 sample that was analyzed by microprobe), Sc-rich regions were found to exist in some of them by SEM (see Figure 32 for an image of the same hot-pressed GSGG-16 sample). Because of these findings of excess Sc, the final batch, GSGG-22, was synthesized with a lower level of excess Sc (see Table 2). After both sintering up to $1625^{\circ} \mathrm{C}$ and hot-pressing at $1350^{\circ} \mathrm{C}$, samples from this batch reached only 6.33 $\mathrm{g} / \mathrm{cm}^{3}$ and were no more transparent than previous materials. 


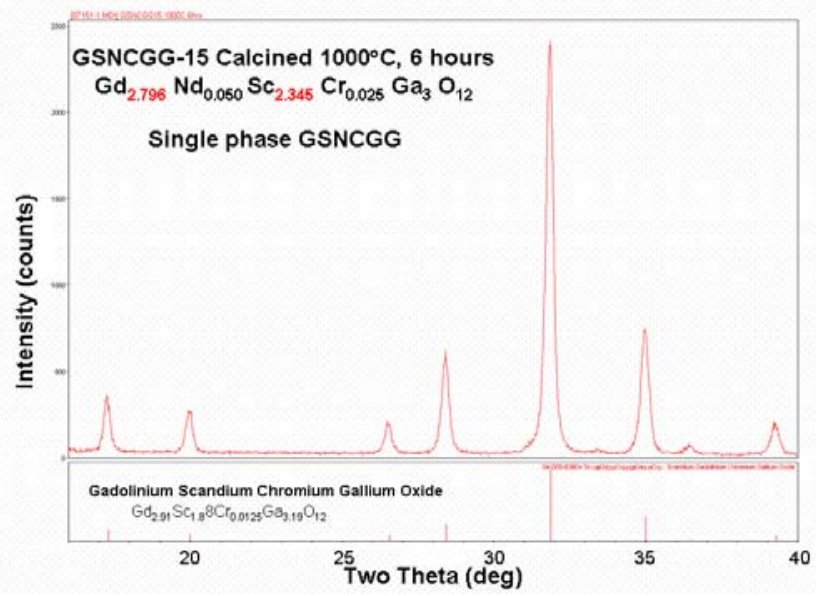

Figure 30. XRD pattern of GSGG-15 powder calcined at $1000^{\circ} \mathrm{C}$ for 6 hrs showing single phase.

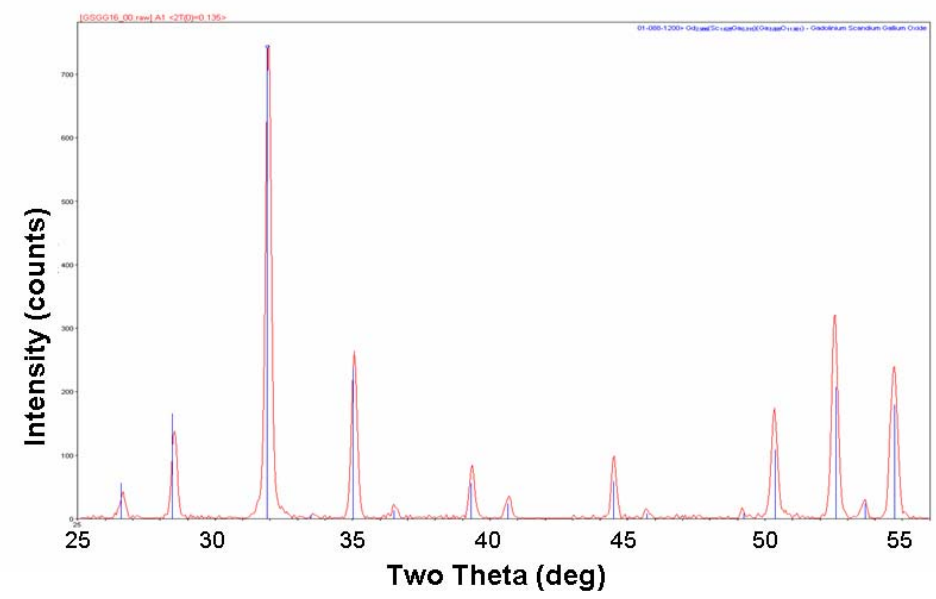

Figure 31. XRD pattern of hot-pressed GSGG-16 showing single phase garnet.

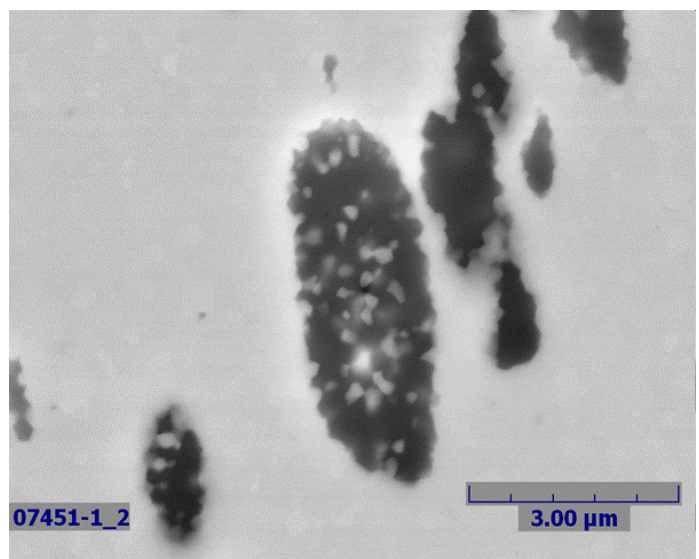

Figure 32. SEM image of a polished surface of a hot-pressed (1350C for 2 hr) GSGG-16 sample showing Sc-rich regions (dark areas). 
To summarize the sintering and hot-pressing of the GSGG materials, transparent materials were only produced by hot-pressing and these turned opaque with subsequent heating above $\sim 1300^{\circ} \mathrm{C}$. The sintered materials were only translucent even though they reached similar densities to the hot-pressed materials and sintering them at higher temperatures or for longer times did not improve their transparency. The reason for this is uncertain. One possibility is that the sintered materials had slightly higher porosity (within the error of measurement) and/or larger pores than the hot-pressed materials that were somewhat transparent. If porosity is the source of the scattering, then hot-isostatically pressing the sintered materials could eliminate this porosity and make the samples transparent. Samples were submitted for HIP treatment but had not been received by the end of the program. Another possibility is that there is another source of scattering, possibly related to the grain boundary structure that forms at temperatures above $1300^{\circ} \mathrm{C}$. This would also explain why the hot-pressed materials turned opaque when annealed at high temperature. In conclusion, with improved stoichiometry control and improved processing, using clean room conditions to further eliminate contamination, high-quality transparent $\mathrm{Cr}$,Nd:GSGG can be produced using the basic processing developed in this work along with hotpressing.

\section{Conclusions}

While the ultimate goal of producing laser quality transparent ceramic Nd:YAG and $\mathrm{Cr}, \mathrm{Nd}$ :GSGG was not achieved, significant progress was made in all steps of the fabrication process for both materials. Chemical precipitation synthesis techniques were developed for precursor powders of both materials and were transferred to Org. 2454 for routine production. The stoichiometry control of up to 5 metal was demonstrated and the precursor powders produced uniform, easily crystallizable, nano-size garnet powders. The calcined crystalline garnet powders were able to be milled ultrasonically without introducing significant contamination and to be formed into uniformly packed compacts using colloidal techniques. The compacts of both materials were sintered to nearly full density at moderate temperatures $\left(\sim 1500^{\circ} \mathrm{C}\right)$ to form translucent ceramics. Understanding of the sintering process allowed modification of the sintering conditions to avoid the formation of large or intergranular pores, that once formed cannot be removed. Control of stoichiometry to avoid second phase formation was problematic due in part to the difficulty detecting the second phases at low concentrations. Samples of both materials that were visually transparent were produced of both materials by hotpressing. With further refinement of the stoichiometry based on the knowledge gained in this work coupled with clean bench processing, high quality transparent hot-pressed should be readily produced with follow-on work. Production by pressureless sintering is also within reach for Nd:YAG although much less certain for the Cr,Nd:GSGG. 


\section{References}

1. W.F. Krupke, M.D. Shinn, J.E. Marion, J.A. Caird and S.E. Stokowski, "Spectroscopic, optical and thermochemical properties of neodymium- and chromium-doped gadolinium scandium gallium garnet,” J. Opt. Soc. Am. B, 3 (1986), 102-114.

2. Polycrystalline Ceramic YAG, Baikowski Techincal Information, www.baikowski.com.

3. A. Ikesue, Y. L. Aung, T. Taira, T. Kamimura, K. Yoshida and G.L. Messing, "Progress in ceramic lasers,” Annu. Rev. Mater. Res., 2006, 36 397-429, (2006).

4. A. Ikesue, T. Kinoshita, K. Kamata and K. Yoshida, "Fabrication and optical properties of high-performance polycrystalline Nd:YAG ceramics for solid-state laser,” J. Am. Ceram. Soc., 78 1033-1040 (1995).

5. A. Ikesue, I. Furusato, and K. Kamata, "Polycrystalline transparent YAG ceramics by a solid-state reaction method,” J. Am. Ceram. Soc., 78 225-28 (1995).

6. A. Ikesue, K. Kamata and K. Yoshida, "Effects of neodymium concentration on optical characteristics of polycrystalline Nd:YAG laser materials,” J. Am. Ceram. Soc., 79 1921-26 (1996).

7. N. A. Torporov, I. A. Bondar, F. Y. Galakhov, X. S. Nikogosyan and N. V. Vinogradova, Izv. Akad. Nauk SSSR, Ser. Khim., No. 7, 1162 (1964).

8. J. Lu, J. Song, M. Prabhu, J. Xu, and K. Ueda, "High-power $\mathrm{Nd} \mathrm{Y}_{3} \mathrm{Al}_{5} \mathrm{O}_{12}$ ceramic laser," Jpn. J. Appl. Phys. 39 (Pt 2) L 1048-50 (2000).

9. J. Lu, K. Ueda, H. Yagi, T. Yanagitani, Y. Akiyama and A. Kaminskii, "Neodymium doped yttrium aluminum garnet nanocrystalline ceramics: a new generation of solid-state laser and optical materials,” J. Alloys Compounds 341 220-25 (2002).

10. T. Yanagitani, H. Yagi and H. Yamazaki, "Production of fine powder of yttrium aluminum garnet,” Japan Patent JP10101411 (1998).

11. T. Yanagitani, H. Yagi and A. Ichikawa, "Production of yttrium-aluminum-garnet of fine powder,” Japan Patent JP10101333 (1998).

12. J.-G. Li, T. Ikegami, J-H. Lee and T. Mori, "Well-sinterable $\mathrm{Y}_{3} \mathrm{Al}_{5} \mathrm{O}_{12}$ powder from carbonate precursor," J. Mater. Res. 15 1514-23 (2000).

13. J.-G. Li, T. Ikegami, J-H. Lee and T. Mori, "Low-temperature fabrication of transparent yttrium aluminum garnet (YAG) ceramics without additives," J. Am. Ceram. Soc. 83 961-63 (2000).

14. J. Nicolas, J. Coutres, J.P. Coutres and B. Boudot, " $\mathrm{Sm}_{2} \mathrm{O}_{3}-\mathrm{Ga}_{2} \mathrm{O}_{3}$ and $\mathrm{Gd}_{2} \mathrm{O}_{3}-\mathrm{Ga}_{2} \mathrm{O}_{3}$ phase diagrams,” J. Sol. State Chem. 52 101-113 (1984).

15. V. G. Ostroumov, Yu. S. Privis, V. A. Smirnov and I. A. Shcherbakov, "Sensitizing of $\mathrm{Nd}^{3+}$ luminescence by $\mathrm{Cr}^{3+}$ in gallium garnets," J. Opt. Soc. Am. B 3 81-94 (1986).

16. 14 O.V. Gorshkova and E.S. Lukin, "Synthesis of gadolinium-gallium garnet," Steklo Keram., 39 (1982), 23-24. [Glass Ceram., 39 (1982), 299-301]

17. O.V. Gorshkova and E.S. Lukin, "A dense ceramic based on gadolinium-gallium garnet," Steklo Keram., 39 (1982) 18-19. [Glass Ceram., 39 (1982), 609-612]

18. P. J. Brannon, “Gain in pulsed x-ray irradiated Cr,Nd:GdScGa-garnet,” Appl. Phys. Lett. 66 151-52 (1995).

19. A. Vaddigiri, K. Simmons-Potter, W. J. Thomes and D. C. Meister, "Radiation-induced optical response of single-crystal and polycrystalline YAG," in Optical Technologies for Arming, Safing, Fuzing and Firing, ed. By William J. Thomes, Fred M. Dickey, Proc. SPIE Vol. 5871, 587108 (2005). 
20. E.E. Hellstrom, R.D. Ray, and C. Zhang, "Preparation of gadolinium gallium garnet by solidstate reaction of the oxides," J. Am. Ceram. Soc., 72 1376-1381 (1989).

21. G.J. Zhao, T. Li, X.M. He, and J. Xu, "Preparation of gadolinium gallium garnet polycrystalline material by coprecipitation method," Mater. Lett., 56 1098-1102 (2002).

22. D. Sun, Q. Zhang, Z. Wang, J. Su, C. Gu, A. Wang and S. Yin, “Co-precipitation synthesis and sintering of nanoscaled $\mathrm{Nd}: \mathrm{Gd}_{3} \mathrm{Ga}_{5} \mathrm{O}_{12}$ polycrystalline material,” Mater. Sci. and Eng. A, 392, p. 278-81 (2005).

23. Z.L. Luo, M.L. Lu, J. Bao, W.H. Liu, and C. Gao, “Co-precipitation synthesis of gadolinium gallium garnet powders using ammonium hydrogen carbonate as the precipitant,” Mater. Lett., 59 (2005), 1188-1191.

24. F. Lange, "Powder processing science and technology for increased reliability,” J. Am. Ceram. Soc., 72 3-15 (1989).

25. R. Zeng and B. Rand, "Improvement of true green porosity, sinterability and microstructure in alumina ceramics by filter pressing,” J. Mater. Sci. Technol., 21 105-8 (2005).

26. L. Zych and K. Haberko, "Filter pressing and sintering of a zirconia nanopowder," J. Eur. Ceram. Soc., 26 373-8 (2006).

27. Y. Hirata, M. Nakamura, M. Miyamoto, Y. Tanaka, and X. H. Wang, "Colloidal consolidation of ceramic nanoparticles by pressure filtration," J. Am. Ceram. Soc., 89 1883-9 (2006). 


\section{Distribution List}

$\begin{array}{llll}1 & \text { MS0344 } & \text { L. S. Weichman } & 02626 \\ 1 & \text { MS0959 } & \text { J. T. Gibson } & 02454 \\ 1 & \text { MS1245 } & \text { S. J. Lockwood } & 02454 \\ 1 & \text { MS1245 } & \text { P. Yang } & 02454 \\ 5 & \text { MS1411 } & \text { T. J. Garino } & 01816 \\ 1 & \text { MS1411 } & \text { D. L. Moore } & 01816 \\ 1 & \text { MS1411 } & \text { E. D. Spoerke } & 01816 \\ 1 & \text { MS1411 } & \text { J. A. Voigt } & 01816 \\ 1 & \text { MS1423 } & \text { R. L. Schmitt } & 01128 \\ 1 & \text { MS90123 } & \text { D. L. Chavez } & 01011 \text { (electronic copy) } \\ 1 & \text { MS0899 } & \text { Central Technical Files } & 08944 \text { (electronic copy) } \\ 1 & & \text { Technical Library } & 09536 \text { (electronic copy) }\end{array}$




\section{Sandia National Laboratories}

